\title{
Beneficial Effects of Dietary Polyphenols on Gut Microbiota and Strategies to Improve Delivery Efficiency
}

\author{
Amit Kumar Singh ${ }^{1,+}+\mathbb{D}_{\text {, Célia Cabral }}{ }^{2,+}{ }^{\mathbb{C}}$, Ramesh Kumar ${ }^{1}$, Risha Ganguly ${ }^{1}$, \\ Harvesh Kumar Rana ${ }^{1}$, Ashutosh Gupta ${ }^{1}(\mathbb{D})$, Maria Rosaria Lauro ${ }^{3} \mathbb{D}$, Claudia Carbone $^{4} \mathbb{D}_{\text {, }}$ \\ Flávio Reis $2,5, *(\mathbb{D}$ and Abhay K. Pandey $1, *$ (D) \\ 1 Department of Biochemistry, University of Allahabad, Allahabad 211002, India; \\ amitfbs21@gmail.com (A.K.S.); rameshbiochem91@gmail.com (R.K.); rishaganguly53@gmail.com (R.G.); \\ harshversity@gmail.com (H.K.R.); ashutosh8998@gmail.com (A.G.) \\ 2 Coimbra Institute for Clinical and Biomedical Research (iCBR), Faculty of Medicine; \& CIBB Consortium, \\ University of Coimbra, 3000-548 Coimbra, Portugal; celia.cabral@fmed.uc.pt \\ 3 Laboratory of Pharmaceutical Technology, Department of Pharmacy, University of Salerno, 84084 \\ Fisciano (SA), Italy; lauro@unisa.it \\ 4 Laboratory of Drug Delivery Technology, Department of Drug Sciences, University of Catania, \\ 95125 Catania, Italy; ccarbone@unict.it \\ 5 Institute of Pharmacology \& Experimental Therapeutics, Faculty of Medicine; University of Coimbra, \\ 3000-548 Coimbra, Portugal \\ * $\quad$ Correspondence: freis@fmed.uc.pt (F.R.); akpandey23@rediffmail.com or akpandey@allduniv.ac.in (A.K.P.) \\ + These authors contributed equally to this work.
}

Received: 3 August 2019; Accepted: 9 September 2019; Published: 13 September 2019

\begin{abstract}
The human intestine contains an intricate ecological community of dwelling bacteria, referred as gut microbiota (GM), which plays a pivotal role in host homeostasis. Multiple factors could interfere with this delicate balance, including genetics, age, antibiotics, as well as environmental factors, particularly diet, thus causing a disruption of microbiota equilibrium (dysbiosis). Growing evidences support the involvement of GM dysbiosis in gastrointestinal (GI) and extra-intestinal cardiometabolic diseases, namely obesity and diabetes. This review firstly overviews the role of GM in health and disease, then critically reviews the evidences regarding the influence of dietary polyphenols in GM based on preclinical and clinical data, ending with strategies under development to improve efficiency of delivery. Although the precise mechanisms deserve further clarification, preclinical and clinical data suggest that dietary polyphenols present prebiotic properties and exert antimicrobial activities against pathogenic GM, having benefits in distinct disorders. Specifically, dietary polyphenols have been shown ability to modulate GM composition and function, interfering with bacterial quorum sensing, membrane permeability, as well as sensitizing bacteria to xenobiotics. In addition, can impact on gut metabolism and immunity and exert anti-inflammatory properties. In order to overcome the low bioavailability, several different approaches have been developed, aiming to improve solubility and transport of dietary polyphenols throughout the GI tract and deliver in the targeted intestinal regions. Although more research is still needed, particularly translational and clinical studies, the biotechnological progresses achieved during the last years open up good perspectives to, in a near future, be able to improve the use of dietary polyphenols modulating GM in a broad range of disorders characterized by a dysbiotic phenotype.
\end{abstract}

Keywords: dietary polyphenols; gut microbiota; dysbiosis; gastrointestinal diseases; metabolic disorders; delivery systems 


\section{Introduction}

Hippocrates has been cited as saying "death sits in the bowels" and "bad digestion is the root of all evil" in around 400 B.C., suggesting the important role of the human intestine in health and disease. Gut microbiota (GM) is the collective community of microorganisms living in the gastrointestinal (GI) tract. Approximately 100 trillions of microorganisms, consisting mainly of bacteria, inhabits in the human GI tract [1]. Viruses, protozoa and eukaryotic organisms, such as fungi, are also present in a small number. In the adult GI tract about $90 \%$ of the bacteria fit in the phyla Bacteroidetes (Gram-negative) and Firmicutes (Gram-positive), while other phyla are present in much lower abundance, such as Actinobacteria (Gram-positive), namely Bifidobacterium, Proteobacteria (Gram-negative) and Verrucomicrobia (Gram-negative), namely Akkermansia muciniphila (Gram-negative) [1,2].

In spite of the fact that people have several hundreds of microbial species inside their gut, newer findings obtained by the Human Microbiome Project and other relevant studies demonstrate that microbial composition is highly variable between individuals [3]. Bacterial colonization starts in utero and GM composition changes throughout the entire life, but the main changes, in number and in diversity, occur during the breast-feeding period and at the beginning of solid food ingestion. The number, type and function of microorganisms differ throughout the GI tract but the bulk is found inside the large intestine, participating in fermentation of undigested food components, particularly carbohydrates and fibers, among other relevant functions. The main roles of GM in humans are depicted in Figure 1. Apart from affording protection against enteropathogens and absorb nutrients from our diet, GM produces several bioactive compounds, some of which are beneficial to health, namely vitamins and some short chain fatty acids (SCFAs), while others are deleterious, such as some metabolites of degradation of amino acids. In addition, host immune defenses, in particular the mucus barrier, are important to protect tissues against harmful effects of some bacteria.

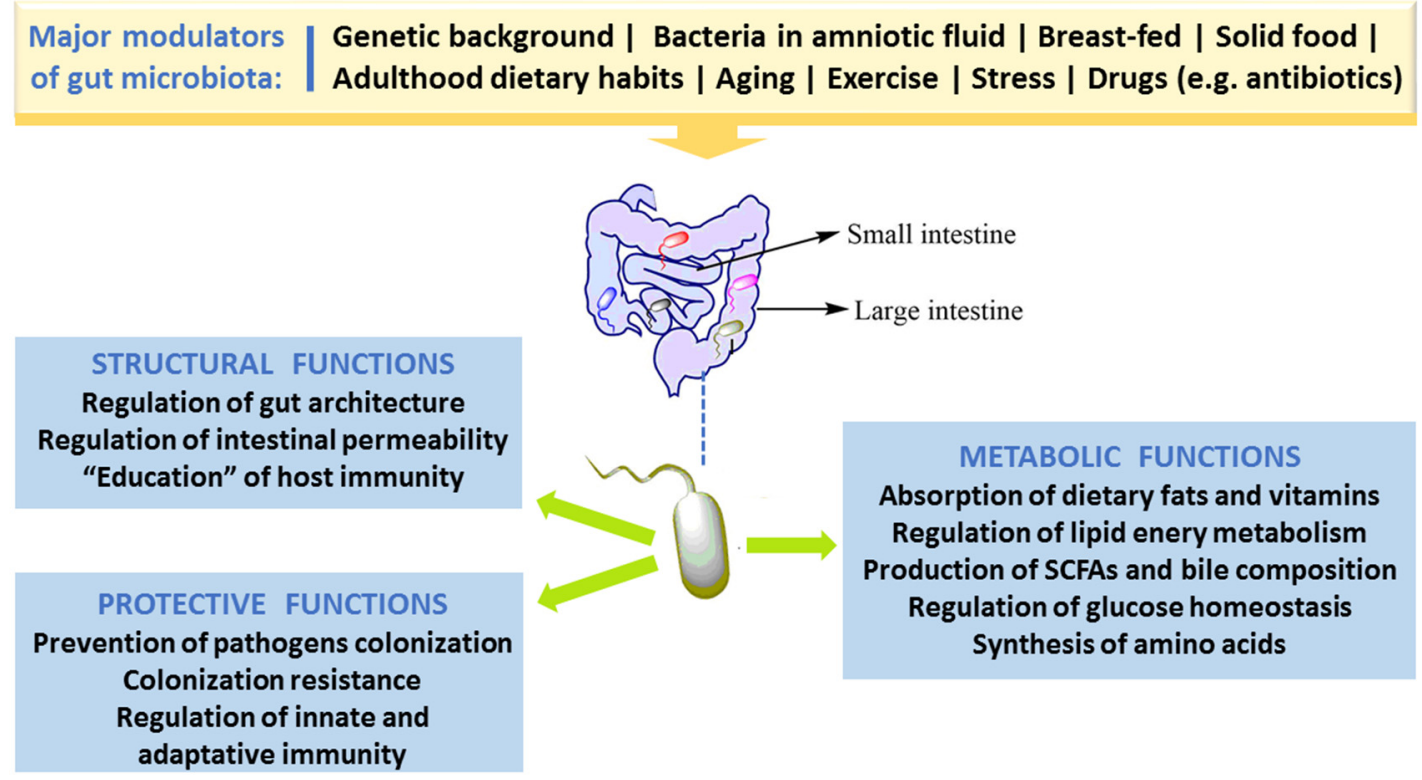

Figure 1. Major factors that modulate gut microbiota and key roles in humans.

Factors responsible for an impaired GM composition and/or function, called dysbiosis, include age, diet and lack of exercise, stress, drugs and xenobiotics $[1,4,5]$. There is increasing evidence supporting an association between dysbiosis and diseases, including those of the GI tract, such as inflammatory bowel disease (IBD), ulcerative colitis (UC), Crohn disease (CD) and colorectal cancer (CRC) [6-8], as well as some extra-intestinal metabolic disorders, including obesity, diabetes and its macro- and microvascular complications [9-11]. Hence, researchers all over the world are searching for therapeutic 
or nutraceutical interventions able to produce a healthy GM equilibrium, eliminating the harmful bacteria (or pathobionts) without affecting the beneficial ones (symbionts).

Dietary polyphenols are natural compounds present in many foods and beverages, namely in fruits, vegetables, cereals, tea, coffee, and wine, among others. Several preclinical and clinical studies have shown their antioxidant, anti-inflammatory, anti-diabetic, anti-cancer, neuroprotective, and anti-adipogenic properties, suggesting a link between polyphenol-rich food consumption and reduction in the incidence of numerous chronic disorders, highlighting them as good candidates for therapeutic/nutraceutical agents [12-15]. However, inside the human body, the chemical structure of the majority of polyphenols is received as a xenobiotic and, thus, the bioavailability of these compounds is highly reduced when compared to that of macro- and micro-nutrients [16]. Because of poor absorption, they are retained in the intestine for longer time where they can promote beneficial effect, namely by affecting the GM community [17]. The impact of dietary polyphenols on gut ecology and the mechanism underlying the putative beneficial effects on GI and extra-intestinal diseases have been depicted during the last decade [18]. In this review, we firstly overview the main features and functions of GM on human health, then we summarize the links between GM dysbiosis and diseases (intestinal and extra-intestinal) and, finally, we critically review the evidences available concerning the impact of polyphenols in GM based on preclinical and clinical data.

\section{Gut Microbiota Dysbiosis and Disease}

\subsection{Gut Morphology and Healthy Microbiota Composition, Diversity and Functions}

The human GI tract, with $250-400 \mathrm{~m}^{2}$ surface area, is one of the chief associations between the host body, external environmental factors and internal antigens. During average lifespan, about sixty tonnes of food and a huge number of external microbes traverses the GI tract, jeopardizing gut integrity. The set of gut microbes- bacteria, archaea, viruses (mainly phages), eukaryotes (mainly yeasts), and other microbial species-, collectively referred as gut microbiota, has jointly developed with the host during millions of years, forming a complex and symbiotic connection [19].

Among the large population of microbial species, about $10^{14}$ cells inhabit the human GI tract. The composition of GM varies along the GI tract in accordance with the morphological and physiological features of digestive system region. The concentration considerably rises from the proximal to the distal gut, together with an enrichment in anaerobes [1,2]. GM composition in the initial proximal portion of the small intestine, predominantly in the duodenum, is identical to that of stomach, given the acidic conditions that results from the chyme of the stomach and biliary and pancreatic secretions. The diversity and number of bacteria increases in the distal portion, from duodenum to ileum, accompanying the gradual increase of $\mathrm{pH}$. In this portion, predominate Lactobacillus and Clostridium species of the Firmicutes phyla, Escherichia coli of the Proteobacteria phyla, as well as Bacteroidetes and gram-negative facultative anaerobes $[1,2]$. The conditions in large intestine, namely in the colon, with a more beneficial nutritional milieu and $\mathrm{pH}$ (5.7-6.8), favor bacterial growth, allowing a more diverse, dense and complex microbial community, essentially composed of obligate anaerobes that survive at low concentrations of oxygen. In the colon, the predominant bacteria are Ruminococcus, Lactobacillus and Clostridium species of the Firmicutes phyla, and Bacteroides and Prevotella of the Bacteroidetes phyla. There are other phyla present in the adult GM, thought in lower abundance, including Actinobacteria, Fusobacteria, Proteobacteria and Verrucomicrobia, as well as some facultative anaerobic bacteria [20,21]. Bacterial composition and functions also varies between the intestinal lumen and the mucus layer of the intestinal mucosa, with a different proportion of anaerobic and aerobic species [1,2,22].

Several recent pieces of evidence support the idea that, against what was previously thought, the microbial colonization of humans starts in utero from maternal commensal microbes, as suggested by the bacteria found in the amniotic fluid, maternal placenta, umbilical cord blood and in meconium (the first "faeces-like excretion") [23-25]. 
GM phylogenetic diversity increases with growth and development of the host; around 2-3 years age, a complex and stable community of microorganisms is formed. Based on different methods of molecular profiling, it is predictable that about one thousand species of bacteria inhabit the gut, mainly anaerobes, including Firmicutes, Bacteroidetes, Actinobacteria, and Proteobacteria. However, the two predominantly phyla Bacteroidetes and Firmicutes constitute over $90 \%$ of all bacterial species in the intestine $[26,27]$.

The healthy GM is stable and contributes to several important physiological host functions (Figure 1). In brief, GM exerts important (i) metabolic effects (co-metabolism), such as synthesis of vitamins and fermentation of carbohydrates, lipids, and proteins; (ii) structural defending properties against pathobionts by preserving integrity and regulating the permeability of gut barrier, thus contributing to host homeostasis; as well as (iii) "education" of host immunity [5]. The intestinal bacteria have ability to synthesize essential and nonessential amino acids. They can produce numerous vitamins and short-chain fatty acids (SCFAs) and are able to carry out biotransformation of bile. Moreover, GM can metabolize some complex oligosaccharides which escaped the digestion, namely several barely digestible polysaccharides, including cellulose, hemicellulose, resistant starches, gums and pectins, unabsorbed sugars and alcohols obtained from the diet. This helps in the retrieval of absorbable substances to the host and in turn the bacteria derive nutrients and energy for their growth and multiplication [5,28]. GM plays a vital role in host immune system development and maintenance. Many findings proved the crucial role of GM in the regulation of antigen presenting cells (APCs) development, namely B-cells, macrophages and dendritic cells, which have capability to protect the body from pathogens while being immuno-tolerant towards gut microbes [29]. Studies with germ-free mice have reported that symbiotic intestinal bacteria are indispensable for the growth and functioning of intestine-linked lymphoid tissues (namely Peyer's patches and mesenteric lymph nodes) and specific lymphocytes [30]. Under normal conditions, GM/immune system interaction stimulates the generation of beneficial responses towards pathogens and the protection of the regulatory pathways associated with the tolerance preservation towards safe antigens. In the developed countries, factors like unwarranted usage of antibiotics and major changes of dietary habits might have influenced the selection of a microbial community composition that fails to create balanced immune responses. This could be ascribed towards the noteworthy increase in autoimmune and inflammatory disorders spanning the last few decades [31].

\subsection{Factors Responsible for Gut Microbiota Alteration (Dysbiosis)}

In the mid-20th century, Metchnikoff first coined the term "dysbiosis" to depict the changes in intestinal bacteria, suggesting a link with immune homeostasis impairment and development of intestinal disorders. In general, dysbiosis can be classified as (1) a decrease in number of symbionts; (2) an unwarranted growth of pathobionts; and (3) a loss of diversity. It has been reported that these 3 different types can co-exist, which is most often the case. Several factors are responsible for an impaired GM composition and/or function-dysbiosis-, including age, diet and lack of exercise, stress, drugs and xenobiotics $[1,4,5]$.

Major GM alterations have been reported in early phase of life, particularly in the first years, when there is a marked increase in numbers and diversity. The maturation and evolution of the human gut microbes is an example of ecological succession [32,33]. After an initial stage of massive new colonization, when the microbial composition is highly variable between individuals, GM undergo successive changes in composition and function until a stable climax community is established. However, major differences have been reported between adult populations of distinct geographic World regions, which might be explained by a diversity of factors, including both genetic and environmental, particularly dietary patterns, hygienic conditions, as well as use of antibiotics and other drugs [34,35]. Furthermore, aging also affects GM composition, changing the number and particularly the diversity of bacteria, with a decrease in the Firmicutes to Bacteroides (F/B) ratio, which might be partially explained by modifications caused by an altered immune-inflammatory milieu-the so called immunosenescence [10]. 
Further causes of aging-related altered GM are the deterioration of physical health, including loss of dentition, impaired salivary function, digestion and transit time in the GI tract, as well as abnormal dietary nutrients resulting in malnutrition [36,37].

Diet is in fact a chief GM modulator, affecting both the composition and functions, thus contributing to maintain health or to favor disease states [38]. For instance, breast milk contains certain oligosaccharides that cause proliferation of Lactobacillus and Bifidobacterium that are predominant in the infant gut and could contribute to immune system development. Similarly, demographic dietary factors result in differential variation in the GM [39]. Rural Africa children, usually consuming plant polysaccharides, had lower faecal levels of Firmicutes and higher of Bacteroidetes (particularly Prevotella and Xylanibacter) when compared with Italian kids that present high amounts of Enterobacteriaceae (especially Shigella and Escherichia). Prevotella and Xylanibacter, in particular, can cause an increment of beneficial SCFAs as a result of cellulose and xylans degradation, suggesting an adaptation to take full advantage of energy extraction from fibre-rich diet. In fact, resistant starch in human diets promote increment of Ruminococcus bromii and Eubacterium rectale in faeces, which show a relationship with fibre fermentation [40]. Several evidences from preclinical models and from humans studies consistently show that high-fat and/or high-sugar diets modifies the GM profile towards dysbiosis, while vegan diet, prebiotics (such as inulin) and/or probiotics causes beneficial effects on GM composition and function, accompanied by reduced adiposity, inflammatory molecules, including lipopolysaccharide (LPS), and other positive effects on metabolic hemostasis [4].

Some recent evidence points to the impact of artificial sweeteners and emulsifiers in GM. Artificial sweeteners, frequently used as sugar alternatives, have been "generally recognized as safe" (GRAS) by regulatory agencies. However, investigations have reported that some of them, including aspartame, sucralose and saccharin, may upset the balance and diversity of GM. In fact, rats orally treated with sucralose for 84 days showed increased gut levels of Clostridia, Bacteroides, and total aerobic bacteria, upregulated expression of bacterial pro-inflammatory genes, as well as disturbed faecal metabolites and augmented faecal $\mathrm{pH}$ [41]. Emulsifiers, which are food additives often present in processed food, have also been associated with altered GM in animals. Mice treated with carboxymethylcellulose and polysorbate-80, two commonly used emulsifiers, revealed decreased numbers of Bacteroidales and Verrucomicrobia together with increased amounts of Proteobacteria, which usually is linked with mucosal inflammation [42]. Altogether the previous examples reinforce the important role of diet in modulation of bacterial-derived metabolites than just influencing the microbiota community for short-term period [43].

Several non-dietary environmental factors are able to impact the human GM towards dysbiosis, including stress, smoking habits and lack of exercise practice, which might be due to, among other factors, the associated pro-oxidative and pro-inflammatory milieu [10]. In addition, medication is a major modulator of the gut ecology. By definition, antibiotics alter GM composition and functions $[44,45]$ and the loss of colonization resistance is an earlier effect of antibiotics on the gut. This loss resulted in much easier rate of colonization by Salmonella following antibiotic treatment. Recent studies in mice reveal that antibiotics cause an increment of gut free sialic acid derived from the host, that can be further used by opportunistic pathogens to growth (namely by Salmonella typhimurium and Clostridium difficile) [46].

\section{Linkage of Dysbiosis to Diseases}

There are increasing evidences in favor of an association between dysbiosis and diseases, including those of the GI tract, such as IBD, UC, CD and CRC, but also some extra-intestinal metabolic disorders, such as obesity, diabetes and macro- and microvascular complications [8-11]. Figure 2 summarizes some of the main linkages of dysbiosis to GI and extra-intestinal metabolic and vascular diseases. 


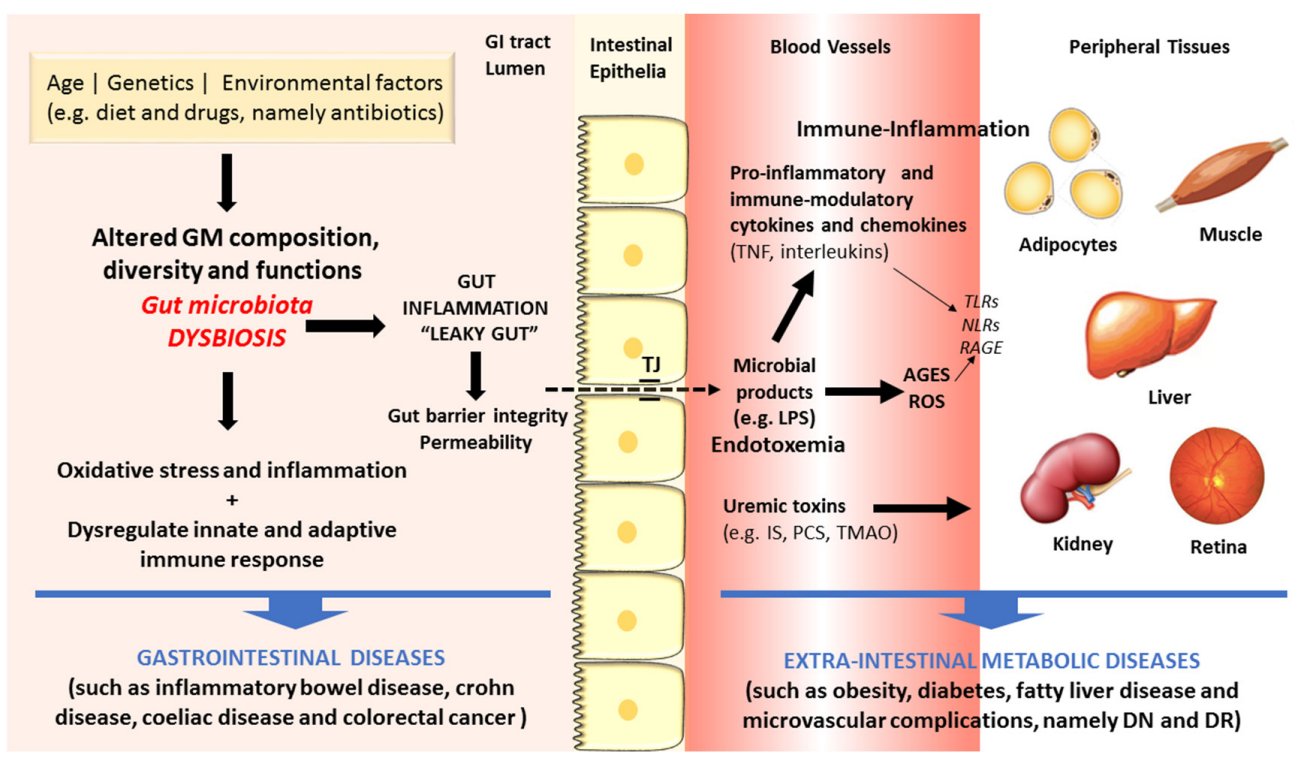

Figure 2. Schematic diagram of some of the main factors and pathways linking dysbiosis to gastrointestinal and extra-intestinal metabolic and vascular diseases.

The gut microbes act in tandem with the defense and immune systems of the host to protect against colonization and invasion of pathogens [21]. Recently, a remarkable amount of experimental data has firmly advocated the important role of GM in human health and disease through several molecular mechanisms. First, the gut microbes have the capacity to increase energy and nutrient extraction from the diet, and it can also alter appetite signaling; second, the human GI flora also offers a physical barrier to protect the host against pathogenic microorganisms, inhibiting their colonization by producing antimicrobial compounds [20,47-49]. During metabolism of xenobiotics, the host and its intestinal microbes generates molecules that play crucial part in exchanging information among host cells and its microbial symbionts. Furthermore, there are relevant uremic toxins derived from the intestinal microbial metabolism of proteins, amino acids and other metabolites, including mainly phenols and indoles bounded to proteins and products of metabolism of phenylalanine and tyrosine, such as p-cresol (PC) and p-cresyl sulfate (PCS), and of tryptophan degradation, such as indoxyl sulfate (IS) and indoleacetic acid [50]. Finally, amines and polyamines are also originated by GM metabolism. A major example is choline, a crucial nutrient for lipid metabolism that is metabolized into toxic trimethylamine and further converted to trimethylamine- $N$-oxide (TMAO) in the liver, which is a promoter of cardiovascular and renal diseases [51,52].

Changed GM composition have been reported in IBDs subjects when compared to controls, though no uniform pattern of alterations has yet been observed [53,54]. The mechanisms underlying the association between GM dysbiosis and evolution of IBDs include the pro-inflammatory and pro-oxidative profile generated in the intestinal lumen and adjacent layers [55,56]. In addition, debates are also going on regarding the crucial role of heat shock proteins (HSPs) in the pathogenesis of IBD, namely due to their participation in several relevant biochemical pathways, such as folding, translocation, and ubiquitinylation of intracellular proteins, as well as due to their capacity to excite innate and adaptive immune response, thus serving as primary autoimmune response targets [57]. The Th17/Treg cells balance, characterized by pro-inflammatory and anti-inflammatory cytokines, which is pivotal for the host's intestinal homeostasis and induction or inhibition of colonic inflammation, is highly influenced by GM composition. Under inflammatory conditions, including IBD and other GI diseases, antigens derived from a dysbiotic GM activate immune cells (namely Th1 and Th17), causing tissue damage, reduction of mucus layer, and exacerbated penetration of microbes in the intestinal tissues. Consequently, there is an augmented uptake of microbial antigens and toll-like receptor (TLR) ligands that perpetuate the immune responses $[8,58]$. 
As above referred, the composition of intestinal microflora is affected by several factors, including lifestyle habits, particularly diet and exercise, which are risk factors for cardiometabolic diseases, such as obesity and T2DM. These conditions have been viewed as the result of an intricate crosstalk between individual genetics, environment influences, including the dietary pattern, as well as the intestinal microflora [59]. Increasing evidences coming from preclinical and clinical studies support the existence of a dysbiotic GM in obesity and T2DM, characterized by lower diversity and resilience [60]. The putative association between dysbiosis and the development of obesity, T2DM and its serious vascular complications has been suggested based on several distinct mechanisms (Figure 2). In brief, GM dysbiosis is a trigger for gut barrier integrity breakdown, with changes on the expression of tight proteins, followed by augmented permeability and consequent translocation from the gut lumen to the bloodstream of bacteria fragments, namely lipopolysaccharide (LPS) and peptidoglycan (PG), and uremic toxins, thus inducing endotoxemia, also referred as a low-grade inflammation state [61,62]. The so-called microbe-associated molecular pattern (MAMP) cause a pro-inflammatory response by binding to toll-like receptors (TLRs), namely TLR4, which evokes a cascade of responses that culminate in pro-inflammatory molecules' release, which will then affect glucose and insulin metabolism and/or signaling [63]. This is further fueled by advanced glycation end products (AGEs) and other oxidative pathways which are deeply involved in the metabolic impairment in obesity and diabetes development. Concomitantly, several evidences strongly suggest that signals coming from the dysbiotic GM modulate immunometabolism by interfering with epithelial and immune cells, generating an immune-inflammatory milieu that favors the progression of diabetes and its complication [10]. In fact, diabetic gut dysbiosis seems to contribute not only to obesity and diabetes development but also to the progression of some of its main microvascular complications, including diabetic retinopathy (DR) and nephropathy (DN). It is suggested that an increase of circulating bacterial endotoxins, particularly LPS, might play a major role in the low-grade inflammation typical of obesity, diabetes and microvascular complications. The translocation of bacterial components and other microbial-derived products through the impaired intestinal barrier to the systemic circulation can contribute to the pro-inflammatory and pro-oxidative profile found in DN and DR, as well as to the overactivated innate and adaptive immunity [10]. These mechanisms, overall, can be pivotal to the progression of metabolic and vascular complications of diabetes (Figure 2).

The question remains whether dysbiosis is directly linked to metabolic disorders, particularly obesity, T2DM and its vascular complications, or whether the impaired GM composition is an adaptation to alteration of host's diet and other modulatory factors. There following findings might help to achieve valid answers: (i) microbiota transfer from lean donors into subjects with metabolic disease causes amelioration of insulin sensitivity and (ii) change in human's diet patterns promote a quick and reversible alteration in the composition of dominant GM members $[64,65]$.

\section{Effects of Polyphenols on Gut Microbiota}

\subsection{Major Classes of Polyphenols}

Dietary polyphenols are compounds of natural origin present in food items such as vegetables, fruits, cereals, tea, coffee, dark chocolate, cocoa powder, and wine. Chemically, these compounds constitute a big heterogeneous collection of compounds, but with structural units common in all phenolic compounds (hydroxylated aromatic rings or phenol rings) $[13,66]$. According to the number of phenol rings that they contain and the structural elements binding these rings, the phenolic compounds are divided in groups. The main groups of dietary polyphenols are: phenolic acids, flavonoids, tannins, stilbenes and diferuloylmethanes $[13,66]$.

Figure 3 shows the chemical structures of some of the principal classes of dietary polyphenols. Phenolic acids are compounded by a phenol ring and a carboxylic function and are divided in benzoic acid derivatives (gallic and protocatechuic acids) and cinnamic acid derivatives ( $p$-coumaric, caffeic and ferulic acids). Stilbenes are hydrocarbons with a trans-ethene double bond replaced by a phenyl 
group on both carbon atoms of the double bond [67]. They appear in low percentage in plants, being resveratrol and its isomer trans-resveratrol the most abundant, usually found in grapes and wine. Flavonoids comprise more than 10,000 natural compounds, being nearly ubiquitous in plants (more than 9000 species) $[13,66,67]$. These compounds have a huge structural diversity, but are derived from a common biosynthetic pathway, the phenylpropanoid metabolic pathway, which incorporates precursors from the shikimic acid and acetate-malonate pathways, lead; well-known examples are kaempferol, quercetin, luteolin, (epi)catechin, (epi)gallocatechin, etc. Tannins are polyphenolic compounds that precipitate proteins, in especially salivary proteins, giving them an astringent character. This property explains their protective role in plants against pathogens and herbivores. They are water-soluble polyphenols with high molecular weight (500-3000 Da), classically divided in condensed tannins or proanthocyanidins (polymers of flavan-3-ol units) and hydrolysable tannins (esters of phenolic acids and a cyclic polyalcohol, usually glucose). Diferuloylmethanes are a small group of phenolic compounds; a well-known compound belonging to this class is curcumin, whose major source is the spice turmeric [66].<smiles>Oc1ccc(C2Oc3cc(O)cc(O)c3CC2O)c(O)c1</smiles>

A
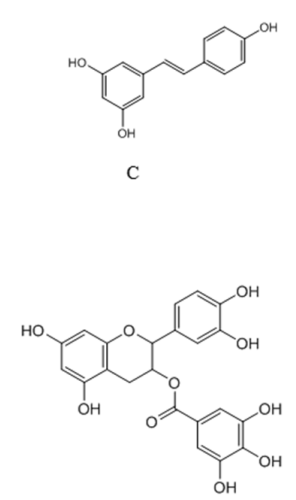

E

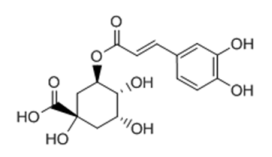

G
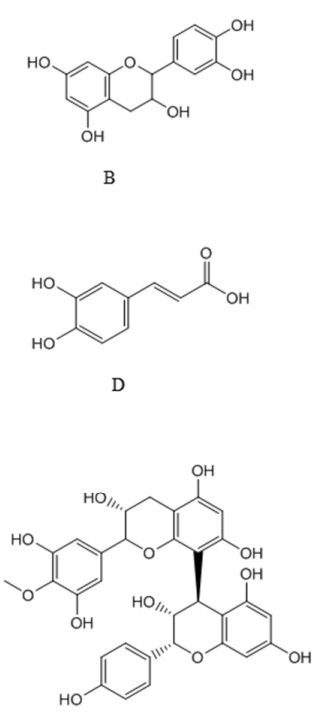

F

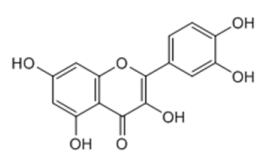

$\mathrm{H}$

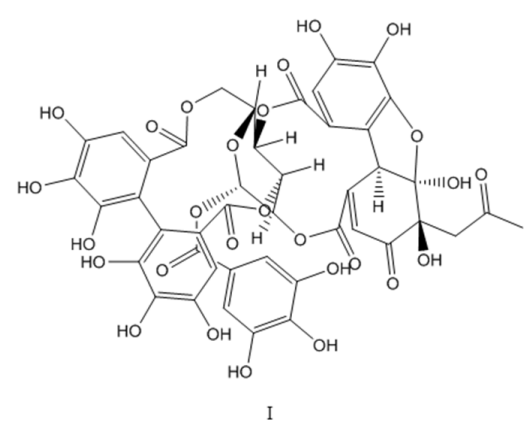

Figure 3. Structure of main polyphenols classes. A: catechins; B: Epicathechins; C: Resveratrol; D: Caffeic acid; E: Proanthocyanidin; F: Epicatechin gallate; G: chlorogenic acid; H: Quercetin; I: Ellagitannin. 


\subsection{Interplay between Polyphenols and GM and Impact on Disease}

Once consumed, dietary polyphenols are apparently perceived as xenobiotics in humans and their biological availability is reasonably poor as compared with micro- and macro-nutrients. Moreover, structural complexity and polymerization also affect their absorption in small intestine [68]. Absorption of the ingested polyphenol in the small intestine is very low (about 5-10\%). The left over polyphenols (90-95\%) may accumulate up to the millimolar range in the large intestine along with the bile conjugates released into the lumen and are exposed to the gut microbial enzymatic activities [69]. Recent studies support that dietary phenolic substances reaching the gut microbes, as well as the aromatic metabolites generated, may modify and produce variations in the microflora community by exhibiting prebiotic effects and antimicrobial action against pathogenic intestinal microflora [18,70,71]. Figure 4 summarizes the major sources of dietary polyphenols and the potential gut microbiota-associated benefits on human health.

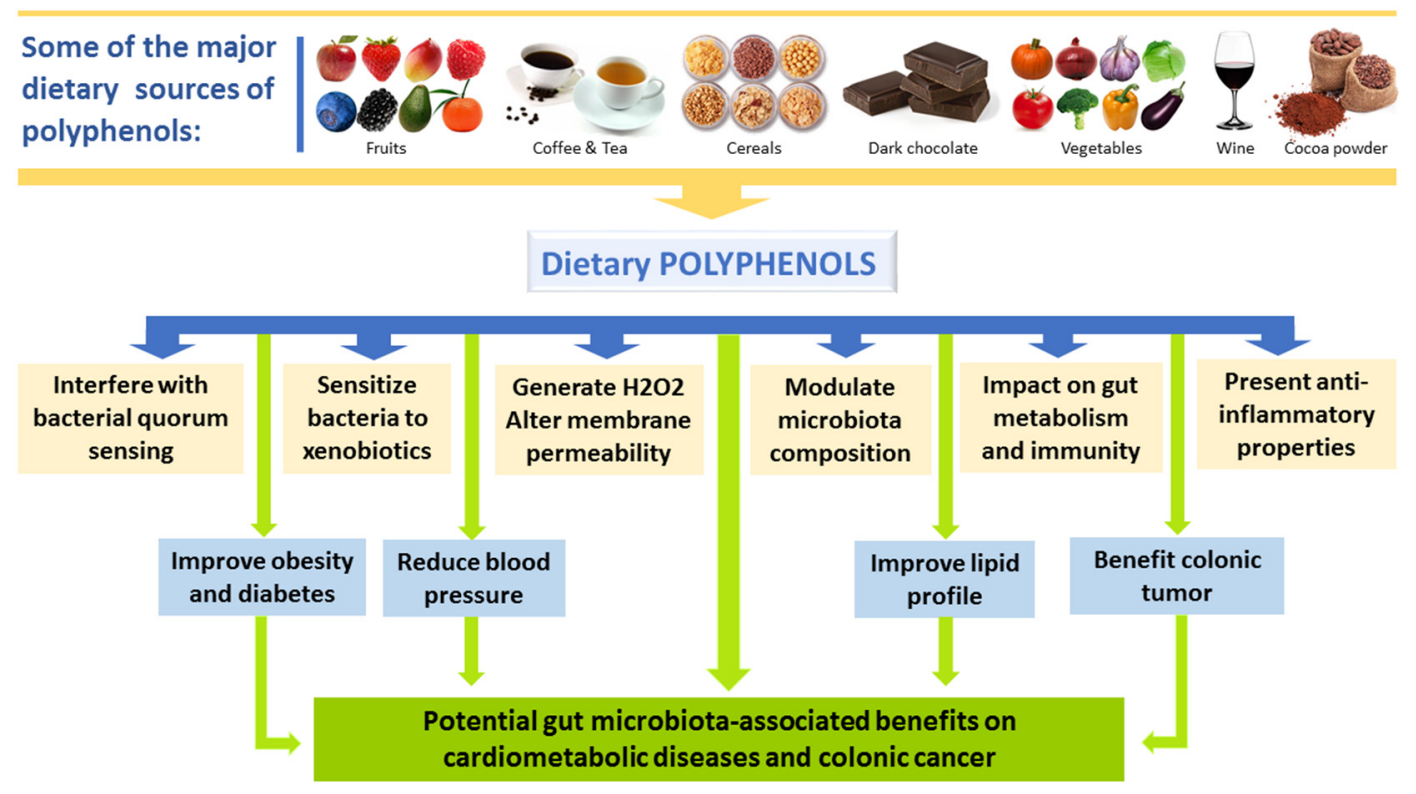

Figure 4. Major sources of dietary polyphenols and the potential gut microbiota-associated benefits on human health.

In humans, the metabolic destiny of dietary polyphenols is a relevant issue that deserves consideration. The small intestine is responsible for the absorption of a low amount of dietary polyphenols, mostly after de-conjugation reactions like de-glycosylation [72]. After absorption into the small intestine, the polyphenolic compounds having lesser complexity may pass through biotransformation in the enterocytes and then in the hepatocytes via Phase I (oxidation, reduction and hydrolysis) and especially Phase II (conjugation) reactions. These transformations produce a chain of water-soluble conjugated metabolites (glucuronide, sulfate and methyl derivatives) which are readily released in the systemic circulation for subsequent delivery to organs and excretion by the urine. Polyphenolic backbone of the 90-95\% unabsorbed polyphenols is acted upon by the colonic bacterial enzymes in the large intestine, and consecutively generate metabolites having diverse physiological implications [73].

Colonic microflora may transform the polyphenols into bioactive compounds, which have the ability to influence the intestinal ecology and affect human health. Studies in animals and in humans have shown that prescribed amounts of particular polyphenolic compound may amend the gut microflora composition resulting in inhibition of certain bacterial groups, while others can flourish in the available niche of the ecosystem. Table 1 summarizes the main studies concerning the influence of polyphenols on GM. 
Table 1. Main preclinical and human data reporting the effects of polyphenols on gut microbiota and associated mechanisms.

\begin{tabular}{|c|c|c|c|}
\hline Polyphenol/Source & Condition/Model & Impact on Microbiota and Associated Mechanisms & Ref. \\
\hline \multicolumn{4}{|c|}{ Preclinical data } \\
\hline Epicatechin gallate & $\begin{array}{l}\text { In vitro assay in bacterial } \\
\text { medium }\end{array}$ & $\begin{array}{l}\text { Sensitizes methicillin-resistant } S \text {. aureus to } \\
\text { beta-lactam antibiotics }\end{array}$ & [74] \\
\hline $\begin{array}{l}\text { Green tea and red wine } \\
\text { polyphenols }\end{array}$ & $\begin{array}{l}\text { In vitro assay in bacterial } \\
\text { medium }\end{array}$ & $\begin{array}{c}\text { Inhibits the VacA toxin, a key virulence factor of } \\
\text { Helicobacter pylori }\end{array}$ & [75] \\
\hline Quercetin & $\begin{array}{l}\text { High fat diet (animal } \\
\text { model) }\end{array}$ & $\begin{array}{c}\text { Reduction of BW. Decrease Firmicutes populations, } \\
\text { Erysipelotrichi class and Bacillus genus. } \\
\text { Down-regulation of Erysipelotrichaceae, Bacillus and } \\
\text { Eubacterium cylindroides }\end{array}$ & [76] \\
\hline $\begin{array}{c}\text { Proanthocyanidin rich red } \\
\text { wine extract }\end{array}$ & $\begin{array}{l}\text { Colon cancer (animal } \\
\text { model) }\end{array}$ & $\begin{array}{c}\text { Treated rats exhibited considerably lower levels of } \\
\text { Clostridium spp. and higher levels of Bacteroides, } \\
\text { Lactobacillus and Bifidobacterium spp. }\end{array}$ & [77] \\
\hline Coffee and Caffeic acid & $\begin{array}{l}\text { Colon cancer (animal } \\
\text { model) }\end{array}$ & $\begin{array}{c}\text { Intake precisely inhibited colon cancer metastasis and } \\
\text { neoplastic cell transformation in mice by inhibiting } \\
\text { TOPK (T-LAK cell-originated protein kinase) } \\
\text { and MEK1 }\end{array}$ & [78] \\
\hline Resveratrol & $\begin{array}{l}\text { Colonic cancer (animal } \\
\text { model) }\end{array}$ & $\begin{array}{c}\text { Reduced activities of faecal and host colonic mucosal } \\
\text { enzymes, such as } \alpha \text {-glucoronidase, nitroreductase, } \\
\beta \text {-galactosidase, mucinase, and } \alpha \text {-glucosidase }\end{array}$ & [79] \\
\hline Resveratrol & $\begin{array}{l}\text { DSS induced colitis } \\
\text { (animal model) }\end{array}$ & $\begin{array}{c}\text { Stimulated faecal cell counts of Lactobacillus and } \\
\text { Bifidobacterium spp. }\end{array}$ & [80] \\
\hline Polyphenols (from plants) & $\begin{array}{l}\text { In vitro assay in bacterial } \\
\text { medium }\end{array}$ & $\begin{array}{l}\text { Control of food-borne pathogenic bacteria without } \\
\text { inhibitory effect on lactic acid bacteria growth }\end{array}$ & [81] \\
\hline Polyphenols (from algae) & $\begin{array}{l}\text { In vivo assay in TD2M } \\
\text { mice }\end{array}$ & $\begin{array}{l}\text { Hypoglycemic effect together with decreased counts of } \\
\text { Turcibacter and Akkermansia and increase of Alistipes }\end{array}$ & [82] \\
\hline $\begin{array}{l}\text { Polyphenols (Chinese } \\
\text { propolis, Brasilian propolis) }\end{array}$ & $\begin{array}{l}\text { DSS induced colitis } \\
\text { (animal model) }\end{array}$ & $\begin{array}{l}\text { Modulation of the GM composition, namely reduction } \\
\text { of the Bacteroides spp. }\end{array}$ & [83] \\
\hline $\begin{array}{l}\text { Polyphenols (Prunella } \\
\text { vulgaris honey) }\end{array}$ & $\begin{array}{l}\text { DSS induced colitis } \\
\text { (animal model) }\end{array}$ & $\begin{array}{l}\text { Modulation of GM composition, with increased } \\
\text { Bacteroidetes/Firmicutes ratio and restoration of } \\
\text { Lactobacillus spp. populations }\end{array}$ & [84] \\
\hline Polyphenols (from fungi) & $\begin{array}{l}\text { DSS induced colitis } \\
\text { (animal model) }\end{array}$ & $\begin{array}{c}\text { Modulation of GM composition, with reduction of } \\
\text { Firmicutes/Bacteroidetes ratio and restoration of } \\
\text { Lactobacillus spp. populations }\end{array}$ & [85] \\
\hline \multicolumn{4}{|c|}{ Human studies } \\
\hline $\begin{array}{l}(+) \text { Catechin and } \\
(-) \text { Epicatechin }\end{array}$ & $\begin{array}{l}\text { In vitro assay with faecal } \\
\text { samples of healthy } \\
\text { volunteers }\end{array}$ & $\begin{array}{c}\text { Inhibition of Clostridium histolyticum growth and } \\
\text { boosted the growth of members of the Clostridium } \\
\text { coccoides-Eubacterium rectale group and E. coli, while } \\
\text { growth of Lactobacillus Spp. and Bifidobacterium Spp. } \\
\text { remained comparatively unaltered }\end{array}$ & [86] \\
\hline $\begin{array}{c}\text { Proanthocyanidin rich grape } \\
\text { extract }\end{array}$ & $\begin{array}{l}\text { Fecal flora and odor } \\
\text { (healthy adults }\end{array}$ & Significantly increase in the number of Bifidobacteria & [87] \\
\hline Cocoa-derived flavanols & Healthy humans & $\begin{array}{l}\text { Stimulate growth and proliferation of Bifidobacterium } \\
\text { spp. and Lactobacillus spp., together with reduction in } \\
\text { plasma C-reactive protein (CRP) }\end{array}$ & [71] \\
\hline Polyphenols (Red wine) & Human study & $\begin{array}{l}\text { Regular intake results in BP reduction, lipid profile } \\
\text { improvement (e.g., TGs) and decline in uric acid levels, } \\
\text { together with increase in the proliferation of } \\
\text { Bacteroides spp. }\end{array}$ & [88] \\
\hline $\begin{array}{l}\text { Polyphenols (Green tea, } \\
\text { fruits, vinegar wine) }\end{array}$ & Obese volunteers & $\begin{array}{l}\text { Weight lowering effect together with alteration in } \\
\text { gut microflora }\end{array}$ & [89] \\
\hline $\begin{array}{l}\text { Dihydroxylated phenolic } \\
\text { acid }\end{array}$ & $\begin{array}{l}\text { In vitro LPS-induced } \\
\text { inflammation }\end{array}$ & $\begin{array}{l}\text { Exhibits potent anti-inflammatory properties, lowering } \\
\text { the secretion of TNF- } \alpha \text {, IL-1b and IL- } 6 \text { in LPS-induced } \\
\text { peripheral blood mononuclear cells from } \\
\text { healthy individuals }\end{array}$ & [90] \\
\hline Polyphenols (from spices) & Healthy humans & Glucose uptake and appetite modulation & [91] \\
\hline
\end{tabular}

An in vitro study reported that flavan-3-ol monomers, namely, (+)catechin and (-)epicatechin, may have ability of impelling the bacterial population in large intestine [86]. (+)Catechins considerably subdued the growth of Clostridium histolyticum and boosted the growth and development of members of the Clostridium coccoides-Eubacterium rectale group and E. coli, while growth of Lactobacillus spp. 
and Bifidobacterium spp. remained comparatively unaltered. Proanthocyanidin-rich red wine extract has been shown to swing the preponderance of Bacteroides, Propionibacterium and Clostridium spp. towards the predominance of Bacteroides, Bifidobacterium and Lactobacillus spp. in a colon cancer animal model [75]. In another study, resveratrol from grape stimulated faecal cell counts of Lactobacillus and Bifidobacterium spp. in the rodent model of colitis induced by dextran sulfate sodium (DSS) [80].

Mechanisms of action of dietary polyphenols varies in Gram positive and Gram-negative bacteria due to changes in cell membrane structure. Polyphenols have ability to bind bacterial cell membranes in a concentration dependent manner, therefore altering functional aspects of membrane and thus preventing their growth. Catechins, interact with many bacteria (Bordetella bronchiseptica, E. coli, Klebsiella pneumonie, Serratia marcescens, Pseudomonas aeruginosa, Salmonella choleraesis, Bacillus subtilis and Staphylococcus aureus) by producing $\mathrm{H}_{2} \mathrm{O}_{2}$, by changing the microbial cell membrane permeability, as well as by sensitizing bacteria to the effects of antibiotics, as was found with epicatechin gallate in methicillin-resistant $S$. aureus treated with beta-lactam antibiotics [74].

Antimicrobial phenolic rich extracts from dietary spices and medicinal herbal samples (Padang cassia, Chinese cassia, oregano, Japanese knotweed, pomegranate peel and clove) showed ability to control five food-borne pathogenic bacteria (Bacillus cereus, Escherichia coli, Salmonella enterica subsp. enterica serovar typhimurium, Shigella flexneri and Staphylococcus aureus). The probiotic effects were also examined on five lactic acid bacteria (Lactobacillus acidophilus, L. delbrueckii subsp. bulgaricus, L. casei, L. plantarum and L. rhamnosus). The results demonstrated a co-existence with lactic acid probiotic bacteria and none of the edible plant extracts showed inhibitory growth effect except on L. bulgaricus. A possible explanation for these results is that lactic acid bacteria survive in a relatively low $\mathrm{pH}$ environment, producing organic acids during fermentation and detoxifying the phenolic acids through metabolism [81].

Polyphenolics can also hinder with bacterial quorum sensing, that is accomplished by generating, liberating and sensing small signal molecules recognized as auto inducers (oligopeptides in Gram-positive bacteria and acylated homoserine lactones in Gram-negative bacteria) [92]. Green tea and red wine polyphenols powerfully hinder the key toxin of Helicobacter pylori which is known as the VacA toxin [75]. The inhibitory actions of food polyphenols against $H$. pylori may comprise inhibition of urease activity, influencing multiplication of bacteria and destroying bacterial cell membrane integrity, hence causing bacteria to become extra sensitive to xenobiotics like antibiotics and causing collapse of proton motive force via loss of $\mathrm{H}^{+}$ATPase and membrane-associated tasks [93]. Flavanoid B ring may take part in intercalation or $\mathrm{H}$-bonding with nucleic acid base pair stacking, and this could elucidate the inhibitory action of flavonoids on DNA and RNA biosynthesis $[66,94]$. Binding of quercetin to $E$. coli DNA gyrase (GyrB subunit) has been reported to produce the enzyme's ATPase activity [95]. Many mechanisms of polyphenols' action on gut microbiota functions are still not known and additional research efforts are solicited for proper understanding.

Wang et al., investigated the GI protective effects of polyphenols from bee products: Prunella vulgaris honey (PVH) [84] and Chinese and Brazilian propolis [83]. PVH significantly modulated the GM composition in the DDS-induced colitic rats, increasing the Bacteroidetes/Firmicutes ratio and restoring Lactobacillus spp. populations. Similar results were obtained for polyphenols from propolis that significantly reduced the Bacteroides spp. Also mushrooms rich in antioxidant polyphenols compounds are able to modulate GM composition. In particular, Ganoderma lucidum mushrooms showed capacity to reduce the Firmicutes/Bacteroidetes ratios and endotoxin-bearing Proteobacteria levels in the DSS-induced colitis model. In addition, the intestinal barrier integrity was reinforced and endotoxemia attenuated, together with beneficial effects on body weight, inflammation, and insulin resistance [85]. During human intervention study, flavonols were reported to stimulate growth and proliferation of Bifidobacterium spp. and Lactobacillus spp. which might have been partially accountable for the perceived decline in the concentration of plasma C-reactive protein (CRP), an inflammatory blood biomarker and a hallmark of the acute phase inflammatory response [71]. Likewise, in an in vitro model bacterial fermentation of water-insoluble cocoa fractions was related with rise in Lactobacilli 
and Bifidobacteria along with butyrate generation; in addition, alterations in these microbes were linked with substantial decline in plasma trilglycerides and CRP, signifying the prospective benefits associated with the inclusion of flavonol-rich foods in diet [96]. Consumption of red wine polyphenols on regular basis caused noteworthy reductions in the blood pressure, as well, as in plasma triglycerides and HDL-cholesterol levels. The reduction of such parameters might be partially attributable to the polyphenol-mediated induction in the proliferation of Bacteroides spp. [88]. Furthermore, consumption of red wine polyphenols led to a noteworthy decline in uric acid levels. It can be accounted for by the substantial enhancement in Proteobacteria population noticed in this stage, which break down uric acid [97]. The weight-reduction activity of green tea, fruits and vinegar wine in obese individuals may be partially associated with their polyphenol contents that modifies the gut microflora either by the glycan-degrading ability of Bacteroides, that is higher than Firmicutes, or by the metabolic end products resulting from colonic metabolism of polyphenols [89]. Monagas et al. reported that dihydroxylated phenolic acids (3-hydroxyphenylpropionic acid, 3,4-dihydroxyphenylpropionic acid and 3,4-dihydroxyphenylacetic acid) produced from the microbial transformation of proanthocyanidins exhibited potent in vitro anti-inflammatory activities, plummeting the secretion of cytokines namely, TNF- $\alpha$, IL-1 $\beta$ and IL-6 in lipopolysaccharide-induced peripheral blood mononuclear cells from normal individuals [90]. Microbial metabolites of phyto-polyphenols have been shown to decrease the risk in the metabolic syndrome. During a study on in vitro model of protein glycation, Verzelloni et al. revealed that pyrogallol and urolithins, the two microbial metabolites obtained from ellagitannin are highly anti-glycative in comparison to parent polyphenolic compounds. Moreover, protein glycation has been reported to play a vital pathological role in diabetes and associated complications, including blindness [98].

In a randomized, single blind, crossover study, Zanzer et al. (2017), reported that polyphenols from spice like turmeric (curcumin, demethoxycurcumin and bisdemethocycurcumin), star anise (quercetin derivatives, kaempferol derivatives and isorhamnetin derivatives), ginger (gingerols and shogaols) and cinnamon (procyanidins, cinnamic acid, kaempferitrin, cinnamaldehyde and 2-hydroxycinnamaldehyde), lowered cardiometabolic risk acting on the gut through glucose uptake inhibition and appetite modulation [91]. Four standardized beverages $(220 \mathrm{~mL}$ corresponding to 185 $\mathrm{mg}$ of gallic acid equivalents) from flavored water and extract of turmeric (Curcuma longa), star anise (Illicium verum L.), ginger (Zingiber officinale) or cinnamon (Cinnamomum burmannii) were administered at eighteen (11 men and 7 women) randomized volunteers. Interesting results were obtained for turmeric and cynnamon that, before intake of a carbohydrate challenge, reduced the postprandial blood glucose phase without affecting insulin; turmeric reduced the 'desire to eat' and 'prospective consumption', and increased the postprandial levels of the gut hormone PYY (peptide tyrosine-tyrosine) [91].

Another in vivo study was conducted with polyphenols from green algae in high-fat/high-sucrose diet and streptozotocin-induced diabetic mice [82]. An ethanolic extract of Enteromorpha prolifera passed through an ultrafiltration membrane of $3 \mathrm{kDa}$ (EPE3K) was able to repair inflammation of hepatocytes caused by diabetes and to improve the liver cells in T2DM mice. EPE3k treatment had a strong hypoglycemic activity and improved the oral glucose tolerance on streptozotocin-induced diabetic mice. In addition, a decrease of body weight of mice and a hypoglycemic activity were observed, together with a beneficial impact on GM, with a decrease of Turicibacter and Akkermansia and an increase of Alistipes [82].

Several studies have revealed the association between the microbial metabolites of dietary polyphenols and cancer prevention. Results of these studies have demonstrated phylum level variations in the gut microflora of patients with- and without-colorectal cancer. However, some phyla are augmented and others are diminished, but precisely how these modifications influence the cancer progression is not clearly known [99]. Some dietary polyphenolic compounds may also modulate bacterial metabolic enzymes, consequently affecting the risk in cancer patients. For instance, rats fed daily with resveratrol intragastrically $(8 \mathrm{mg} / \mathrm{kg}$ body weight) considerably decreased the activities of faecal and host colonic mucosal enzymes, viz., $\alpha$-glucuronidase, nitroreductase, 
$\beta$-galactosidase, mucinase, and $\alpha$-glucosidase, as compared to control animals $(21 \%, 26 \%, 37 \%$, $41 \%$ and $45 \%$, respectively). The reduction in bacterial enzyme activity was linked with a major decline in colonic tumor occurrence in the resveratrol-supplemented rats as compared with normal control rats, but it is not clear whether these changes resulted from alterations of enzymatic activity within a subpopulation of microflora or a variation in the proportion of particular gut microflora [79]. The stilbene resveratrol has been shown to negatively affect the progression of colon cancer. The resveratrol exhibits anti-inflammatory activity by inhibiting proinflammatory mediators, modulating eicosanoid biosynthesis and inhibiting enzymes including COX-2 (cyclooxygenase-2), IL6 (interleukin 6), TNF- $\alpha$ (tumor necrosis factor-alpha), AP-1 (Activator protein 1), NF-kB (nuclear factor kappa-light-chain-enhancer of activated B cells), and VEGF (vascular endothelial growth factor) [100]. In an in vitro study, COX-2 activity was inhibited by numerous phenolic compounds probably by binding to the enzyme [101]. In mice model, coffee and caffeic acid are reported to inhibit colon cancer metastasis and neoplastic cell transformation by inhibiting TOPK (T-LAK cell-originated protein kinase) and MEK1 [78]. Cardona and co-workers have investigated the influence of certain intestinal polyphenolic metabolites (3,4-dihydroxyphenylacetic acid, 3-(3,4-dihydroxyphenyl)-propionic acid, metabolites of chlorogenic acid/caffeic acid and quercetin) on variation in enzyme activities associated with inflammation and detoxification in LT97 human adenoma cells. They reported upregulation of GSTT2 and a down-regulation of COX-2 which could possibly add to the chemopreventive potential of polyphenols after their metabolic breakdown in the intestine [69].

Overall, dietary polyphenols have shown, both in preclinical and in clinical studies, several benefits on distinct disorders due to effects on GM, although further experimental evidences are still warranted to elucidate the precise molecular mechanisms involved.

\section{Strategies to Improve Efficiency of Pre- and Probiotics Delivery}

As mentioned above, the low bioavailability represents polyphenols' major drawback, which compromises the possible health benefits. This is also true for probiotics since some bacteria cannot freely circulate through the GI tract without being killed. In order to overcome this limitation, among different therapeutic approaches, many strategies have been recently proposed. They are focused on the possibility to allow targeted local delivery to the intestinal region, thus reducing the systemic diffusion, improving the effectiveness of delivering on the appropriate level of the GI tract, which is frequently, and consequently, associated with the occurrence of less side effects [102-104]. Different strategies have been proposed exploiting physiological changes in the intestinal tract, such as $\mathrm{pH}$-sensitive delivery systems, enzyme linkers, pressure-dependent delivery systems, osmotic controlled and prodrugs [105]. In particular, polymers such as Eudragit ${ }^{\circledR}$, Poly (methacrylic acid-co-ethyl acrylate), cellulose acetate phthalate (CAP)), hydroxyl propyl methylcellulose phthalate (HPMCP), have been widely used for coating capsules and tablets [106]. The peculiar properties of micro- and nanoparticles such as size, shape, surface, stability (4S) [107], strongly influence the in vitro and in vivo fate of active compounds, making these carriers a potential valid strategy also for local intestinal region. To improve the polyphenols activity and the intestinal or colon release, different flavonoids spray-dried microcapsule obtained by cellulose derivative with gastro-resistant swelling and controlled release properties were formulated. Satisfying data were obtained at $\mathrm{pH} 1.0$ (USP gastric simulated fluid) with a release $<20 \%$, associated to a complete release of glycosides naringin and rutin at $\mathrm{pH} 7.0$ (USP intestinal simulated fluid). Complete intestinal release of their aglycones was obtained adding surfactants without altering the gastric release [108]. Chung et al. (2014) used two different types of HPMCP (S and L) to coat green tea catechins to improve their digestive stability and intestinal transport [109]. The bioavailability was investigated on in vitro gastrointestinal model coupled with Caco-2 cells. The intestinal transport rate of L-HPMCP showed an increase of 3.47 times in respect to green tea catechins alone and resulted better than S-HPMCP (increase of 1.50 times). In addition, the digestive stability was improved (2.74 times for S-HPMCP and 3.56 times L-HPMCP). Eudragit S100 (ERS100) was used also in presence of PLGA in 2:1 weight ratio to obtain curcumin drug delivery 
microparticles as anti-inflammatory agents in colitis tissues. The carrier showed high curcumin loading, well-controlled timed release for more than $24 \mathrm{~h}$ and possessed a better efficacy on ulcerative colitis with respect to the pure curcumin [110]. To avoid the resveratrol intestinal release, other matrices such as silk fibroin nanoparticles were developed. The intestinal anti-inflammatory was administered intracolonically and evaluated in an experimental model of rat colitis. The resveratrol fibroin nanoparticles showed a high efficacy decreasing the myeloperoxidase activity and inhibiting the expression of TNF- $\alpha$, IL-1, IL- 6 and IL-12. Thus, this approach seems to be an attractive strategy for the controlled release of resveratrol to intestinal inflammation [111]. An interesting approach was the reported by Shinde et al. (2014) that investigated the effects of alginate microencapsulation on synergy between polyphenols apple skin extract (ASPE) and the probiotic bacteria (PB), Lactobacillus acidophilus. [112]. In particular, the survival and growth of $\mathrm{PB}$ alone and formulated was analyzed after 50 days of storage at $4{ }^{\circ} \mathrm{C}$ in milk; $0.5 \%$ of alginate solution was employed to produce PP-core and PP-PB core solution for $1 \%$ alginate, obtained by co-extrusion method. Studies on the antioxidant activity showed a high value for the aqueous PB-aqueous PPs-alginate bead system, due to the great efficacy of ASPE in combating the oxidative stress. Instead, in the presence of ASPE, the PB cell death rate decreased and the Lactobacillus acidophilus shelf life increased. This suggests that the formulation of PB in the presence of ASPE can allow a PB release in a dose higher than the minimal requirement of $10^{-6}-10^{-7} \mathrm{CFU}$, protecting it and offering an approach for benefit also from the antioxidant health effects of PPs. Another probiotic, the yeast Saccharomyces cerevisiae boulardii, was microencapsulated in an alginate-inulin-xanthan gum mixture [113]. There was an increased ability to survive and growth in berry juice for 4 weeks storage at $4{ }^{\circ} \mathrm{C}$. In addition, the microcapsules absorbed different polyphenols and anthocyanins, protecting also them from harsh conditions of the GI environment. This behavior add value to this probiotic formulation due to polyphenols and anthocyanins beneficial effects on microflora and human health. In fact, Fleschhut et al. (2006) demonstrated that the anthocyanins were degraded by intestinal microflora into phenolic acids [114]. They are responsible for the health benefits of dietary anthocyanins [115] which are associated also to a beneficial modulation of the GM, particularly increasing the Bifidobacterium strains [116].

Based on the increasing understanding of GM and its possible targeting, continuous efforts are being developed by researchers all over the world, with the contribution of bioengineers, cell biologists, material chemists, and pharmaceutical technological scientists. A deeper understanding of the roles of polyphenols that can act in synergy with different probiotic strains in modulating GM composition and function, together with epigenetics and metabolomics findings, would allow the development of innovative approaches to prevent and manage targeted microbiota diseases contributing to achieving the goal of personalized drug delivery, nutraceuticals or functional food.

\section{Conclusions and Perspectives}

GM plays a central role in many mechanisms crucial for host physiology and metabolism. Multiple factors, including unhealthy dietary habits, can cause disruption of microbiota equilibrium (dysbiosis), which has been associated with gastrointestinal diseases (namely IBD, among others) as well as with extra-intestinal metabolic disorders, namely obesity and diabetes. Polyphenols, highly present in a wide range of healthy foods (namely vegetables and fruits), have been linked with beneficial effects on multiple disorders, including cardiometabolic, neurodegenerative and oncologic, which might be due to its antioxidant, anti-inflammatory and other cytoprotective properties. Evidence from preclinical and clinical studies suggest that polyphenols are able to express prebiotic properties and exert antimicrobial activities against pathogenic gut microflora. Although the precise mechanisms deserve further clarification, dietary polyphenols have shown benefits in distinct disorders, accompanied by a major impact on GM towards symbiosis. Unfortunately, the therapeutic/nutraceutical use of polyphenols has been seriously compromised by the lower bioavailability and inability to efficiently achieve the targets (tissues/cells/gut bacteria). In order to overcome this limitation, during the last years several approaches have been developed, aiming to transport polyphenols throughout the GI tract and deliver 
the phenolic compounds in the targeted intestinal regions. In addition, probiotic inserted in flavonoids formulations can better reach the target regions and act in a synergic fashion, improving efficiency. Biotechnological advances achieved during recent years have paved the way to efficient use of phenolic compounds targeting GM in a broad range of disorders characterized by a dysbiotic phenotype.

Funding: A.K.S., R.K. and R.G. acknowledge the support from CSIR-New Delhi India in the form of Senior/Junior research fellowship. A.K.S., R.K., R.G., H.K.R., A.G. and A.K.P. also acknowledge DST-FIST India and UGC-SAP India for the financial support provided to Department of Biochemistry, University of Allahabad India. This work was also supported by European Regional Development Fund (FEDER), through Programa Operacional Factores de Competitividade COMPETE2020 (CENTRO-01-0145-FEDER-000012-HealthyAging2020) and by National funds via Portuguese Science and Technology Foundation (FCT): Strategic Projects (UID/NEU/04539/2013 and UID/NEU/04539/2019), and PTDC/SAU-NUT/31712/2017, as well as by COMPETE-FEDER funds (POCI-01-0145-FEDER-007440 and POCI-01-0145-FEDER-031712).

Conflicts of Interest: The authors declare no conflict of interest.

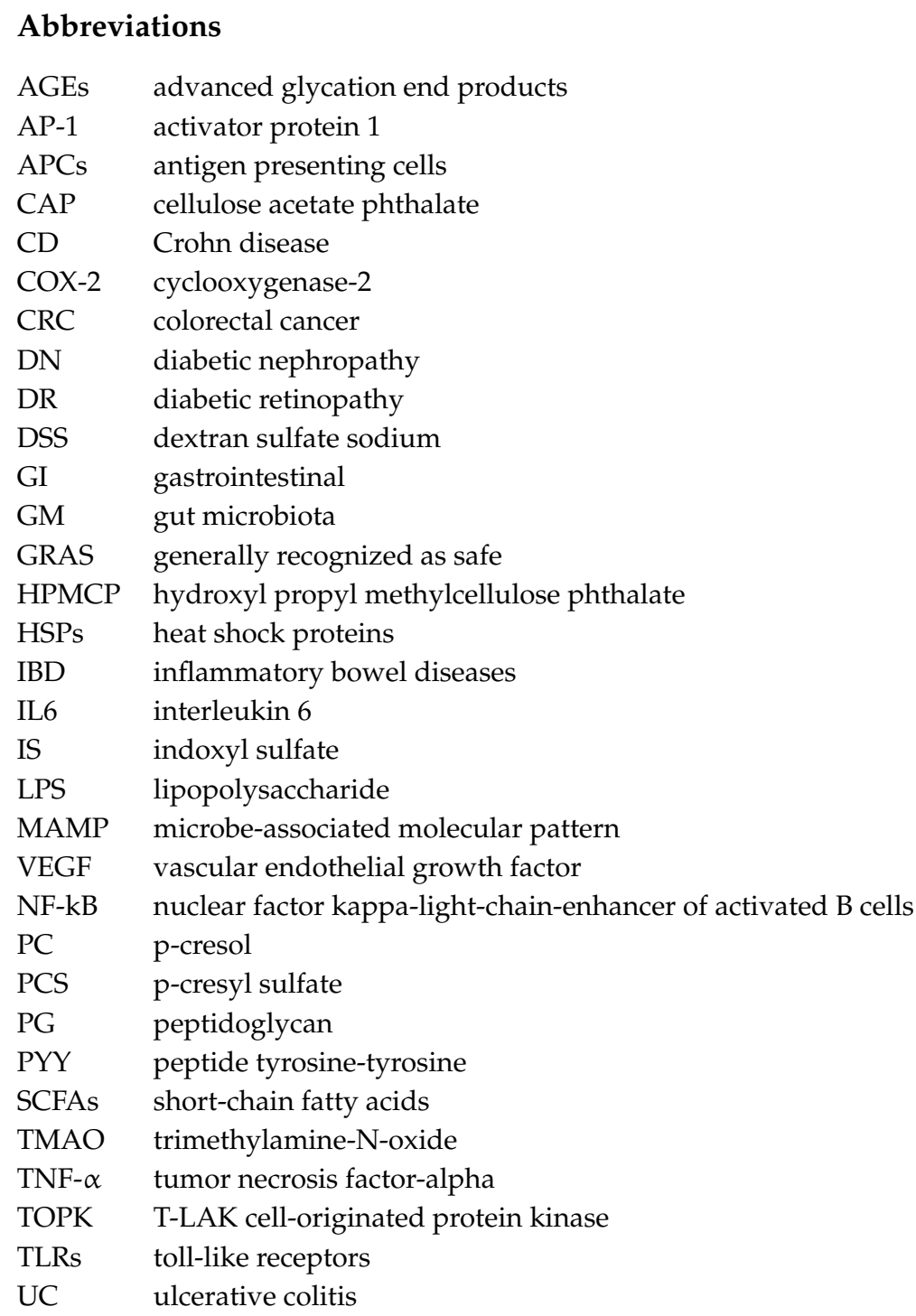




\section{References}

1. Sekirov, I.; Russell, S.L.; Antunes, L.C.M.; Finlay, B.B. Gut Microbiota in Health and Disease. Physiol. Rev. 2010, 90, 859-904. [CrossRef] [PubMed]

2. Eckburg, P.B.; Bik, E.M.; Bernstein, C.N.; Purdom, E.; Dethlefsen, L.; Sargent, M.; Gill, S.R.; Nelson, K.E.; Relman, D.A. Diversity of the Human Intestinal Microbial Flora. Science 2005, 308, 1635-1638. [CrossRef] [PubMed]

3. Huttenhower, C.; Gevers, D.; Knight, R.; Abubucker, S.; Badger, J.H.; Chinwalla, A.T.; Creasy, H.H.; Earl, A.M.; FitzGerald, M.G.; Fulton, R.S.; et al. Structure, function and diversity of the healthy human microbiome. Nature 2012, 486, 207. [CrossRef]

4. Conlon, M.A.; Bird, A.R. The Impact of Diet and Lifestyle on Gut Microbiota and Human Health. Nutrients 2014, 7, 17-44. [CrossRef] [PubMed]

5. Krishnan, S.; Alden, N.; Lee, K. Pathways and functions of gut microbiota metabolism impacting host physiology. Curr. Opin. Biotechnol. 2015, 36, 137-145. [CrossRef]

6. DeGruttola, A.K.; Low, D.; Mizoguchi, A.; Mizoguchi, E. Current Understanding of Dysbiosis in Disease in Human and Animal Models. Inflamm. Bowel Dis. 2016, 22, 1137-1150. [CrossRef]

7. Zhang, M.; Sun, K.; Wu, Y.; Yang, Y.; Tso, P.; Wu, Z. Interactions between Intestinal Microbiota and Host Immune Response in Inflammatory Bowel Disease. Front. Immunol. 2017, 8, 942. [CrossRef]

8. Zuo, T.; Ng, S.C. The Gut Microbiota in the Pathogenesis and Therapeutics of Inflammatory Bowel Disease. Front. Microbiol. 2018, 9, 2247. [CrossRef]

9. Brial, F.; Le Lay, A.; Dumas, M.-E.; Gauguier, D. Implication of gut microbiota metabolites in cardiovascular and metabolic diseases. Cell. Mol. Life Sci. 2018, 75, 3977-3990. [CrossRef]

10. Fernandes, R.; Viana, S.D.; Nunes, S.; Reis, F. Diabetic gut microbiota dysbiosis as an inflammaging and immunosenescence condition that fosters progression of retinopathy and nephropathy. Biochim. Biophys. Acta Mol. Basis Dis. 2018, 1865, 1876-1897. [CrossRef]

11. Pascale, A.; Marchesi, N.; Marelli, C.; Coppola, A.; Luzi, L.; Govoni, S.; Giustina, A.; Gazzaruso, C. Microbiota and metabolic diseases. Endocrine 2018, 61, 357-371. [CrossRef] [PubMed]

12. Crasci, L.; Lauro, M.R.; Puglisi, G.; Panico, A. Natural antioxidant polyphenols on inflammation management: Anti-glycation activity vs. metalloproteinases inhibition. Crit. Rev. Food Sci. Nutr. 2018, 58, 893-904. [CrossRef] [PubMed]

13. Kinger, M.; Kumar, S.; Kumar, V. Some Important Dietary Polyphenolic Compounds: An Anti-inflammatory and Immunoregulatory Perspective. Mini Rev. Med. Chem. 2018, 18, 1270-1282. [CrossRef] [PubMed]

14. Sharma, U.K.; Sharma, A.K.; Pandey, A.K. Medicinal attributes of major phenylpropanoids present in cinnamon. BMC Complement. Altern. Med. 2016, 16, 156. [CrossRef] [PubMed]

15. Singh, A.K.; Bishayee, A.; Pandey, A.K. Targeting Histone Deacetylases with Natural and Synthetic Agents: An Emerging Anticancer Strategy. Nutrients 2018, 10, 731. [CrossRef] [PubMed]

16. Landete, J.M. Updated Knowledge about Polyphenols: Functions, Bioavailability, Metabolism, and Health. Crit. Rev. Food Sci. Nutr. 2012, 52, 936-948. [CrossRef]

17. Duda-Chodak, A.; Tarko, T.; Satora, P.; Sroka, P. Interaction of dietary compounds, especially polyphenols, with the intestinal microbiota: A review. Eur. J. Nutr. 2015, 54, 325-341. [CrossRef] [PubMed]

18. Kawabata, K.; Yoshioka, Y.; Terao, J. Role of Intestinal Microbiota in the Bioavailability and Physiological Functions of Dietary Polyphenols. Molecules 2019, 24, 370. [CrossRef]

19. Thursby, E.; Juge, N. Introduction to the human gut microbiota. Biochem. J. 2017, 474, 1823-1836. [CrossRef]

20. Gill, S.R.; Pop, M.; DeBoy, R.T.; Eckburg, P.B.; Turnbaugh, P.J.; Samuel, B.S.; Gordon, J.I.; Relman, D.A.; Fraser-Liggett, C.M.; Nelson, K.E. Metagenomic Analysis of the Human Distal Gut Microbiome. Science 2006, 312, 1355-1359. [CrossRef]

21. Ursell, L.K.; Haiser, H.J.; Van Treuren, W.; Garg, N.; Reddivari, L.; Vanamala, J.; Dorrestein, P.C.; Turnbaugh, P.J.; Knight, R. The Intestinal Metabolome: An Intersection Between Microbiota and Host. Gastroenterology 2014, 146, 1470-1476. [CrossRef] [PubMed]

22. Li, H.; Limenitakis, J.P.; Fuhrer, T.; Geuking, M.B.; Lawson, M.A.; Wyss, M.; Brugiroux, S.; Keller, I.; MacPherson, J.A.; Rupp, S.; et al. The outer mucus layer hosts a distinct intestinal microbial niche. Nat. Commun. 2015, 6, 8292. [CrossRef] [PubMed] 
23. DiGiulio, D.B.; Romero, R.; Amogan, H.P.; Kusanovic, J.P.; Bik, E.M.; Gotsch, F.; Kim, C.J.; Erez, O.; Edwin, S.; Relman, D.A. Microbial Prevalence, Diversity and Abundance in Amniotic Fluid During Preterm Labor: A Molecular and Culture-Based Investigation. PLoS ONE 2008, 3, e3056. [CrossRef] [PubMed]

24. Koleva, P.T.; Kim, J.; Scott, J.A.; Kozyrskyj, A.L. Microbial programming of health and disease starts during fetal life. Birth Defects Res. Part C Embryo Today Rev. 2015, 105, 265-277. [CrossRef] [PubMed]

25. Satokari, R.; Grönroos, T.; Laitinen, K.; Salminen, S.; Isolauri, E. BifidobacteriumandLactobacillusDNA in the human placenta. Lett. Appl. Microbiol. 2009, 48, 8-12. [CrossRef] [PubMed]

26. Marchesi, J.R.; Adams, D.H.; Fava, F.; Hermes, G.D.; Hirschfield, G.M.; Hold, G.; Quraishi, M.N.; Kinross, J.; Smidt, H.; Tuohy, K.M.; et al. The gut microbiota and host health: A new clinical frontier. Gut 2016, 65, 330-339. [CrossRef]

27. Tanaka, M.; Nakayama, J. Development of the gut microbiota in infancy and its impact on health in later life. Allergol. Int. 2017, 66, 515-522. [CrossRef]

28. Bull, M.J.; Plummer, N.T. Part 1: The Human Gut Microbiome in Health and Disease. Integr. Med. A Clin. J. 2014, 13, 17.

29. Wu, H.-J.; Wu, E. The role of gut microbiota in immune homeostasis and autoimmunity. Gut Microbes 2012, 3, 4-14. [CrossRef]

30. Kim, D.; Zeng, M.Y.; Núñez, G. The interplay between host immune cells and gut microbiota in chronic inflammatory diseases. Exp. Mol. Med. 2017, 49, e339. [CrossRef]

31. Belkaid, Y.; Hand, T.W. Role of the Microbiota in Immunity and Inflammation. Cell 2014, 157, $121-141$. [CrossRef] [PubMed]

32. Koenig, J.E.; Spor, A.; Scalfone, N.; Fricker, A.D.; Stombaugh, J.; Knight, R.; Angenent, L.T.; Ley, R.E. Succession of microbial consortia in the developing infant gut microbiome. Proc. Natl. Acad. Sci. USA 2011, 108, 4578-4585. [CrossRef] [PubMed]

33. Yatsunenko, T.; Rey, F.E.; Manary, M.J.; Trehan, I.; Dominguez-Bello, M.G.; Contreras, M.; Magris, M.; Hidalgo, G.; Baldassano, R.N.; Anokhin, A.P.; et al. Human gut microbiome viewed across age and geography. Nature 2012, 486, 222-227. [CrossRef]

34. De Filippo, C.; Cavalieri, D.; Di Paola, M.; Ramazzotti, M.; Poullet, J.B.; Massart, S.; Collini, S.; Pieraccini, G.; Lionetti, P. Impact of diet in shaping gut microbiota revealed by a comparative study in children from Europe and rural Africa. Proc. Natl. Acad. Sci. USA 2010, 107, 14691-14696. [CrossRef] [PubMed]

35. Lozupone, C.A.; Stombaugh, J.I.; Gordon, J.I.; Jansson, J.K.; Knight, R. Diversity, stability and resilience of the human gut microbiota. Nature 2012, 489, 220-230. [CrossRef] [PubMed]

36. An, R.; Wilms, E.; Masclee, A.A.M.; Smidt, H.; Zoetendal, E.G.; Jonkers, D. Age-dependent changes in GI physiology and microbiota: Time to reconsider? Gut 2018, 67, 2213-2222. [CrossRef] [PubMed]

37. Mariat, D.; Firmesse, O.; Levenez, F.; Guimarăes, V.; Sokol, H.; Doré, J.; Corthier, G.; Furet, J.-P. The Firmicutes/Bacteroidetes ratio of the human microbiota changes with age. BMC Microbiol. 2009, 9, 123. [CrossRef] [PubMed]

38. Claesson, M.J.; Jeffery, I.B.; Conde, S.; Power, S.E.; O'Connor, E.M.; Cusack, S.; Harris, H.M.B.; Coakley, M.; Lakshminarayanan, B.; O'Sullivan, O.; et al. Gut microbiota composition correlates with diet and health in the elderly. Nature 2012, 488, 178-184. [CrossRef]

39. Harmsen, H.J.M.; Wildeboer-Veloo, A.C.M.; Raangs, G.C.; Wagendorp, A.A.; Klijn, N.; Bindels, J.G.; Welling, G.W. Analysis of Intestinal Flora Development in Breast-Fed and Formula-Fed Infants by Using Molecular Identification and Detection Methods. J. Pediatr. Gastroenterol. Nutr. 2000, 30, 61-67. [CrossRef] [PubMed]

40. Tremaroli, V.; Bäckhed, F. Functional interactions between the gut microbiota and host metabolism. Nature 2012, 489, 242-249. [CrossRef]

41. Bian, X.; Chi, L.; Gao, B.; Tu, P.; Ru, H.; Lu, K. Gut Microbiome Response to Sucralose and Its Potential Role in Inducing Liver Inflammation in Mice. Front. Physiol. 2017, 8, 487. [CrossRef] [PubMed]

42. Chassaing, B.; Koren, O.; Goodrich, J.K.; Poole, A.C.; Srinivasan, S.; Ley, R.E.; Gewirtz, A.T. Dietary emulsifiers impact the mouse gut microbiota promoting colitis and metabolic syndrome. Nature 2015, 519, 92-96. [CrossRef] [PubMed]

43. Wu, G.D.; Compher, C.; Chen, E.Z.; Smith, S.A.; Shah, R.D.; Bittinger, K.; Chehoud, C.; Albenberg, L.G.; Nessel, L.; Gilroy, E.; et al. Comparative metabolomics in vegans and omnivores reveal constraints on diet-dependent gut microbiota metabolite production. Gut 2016, 65, 63-72. [CrossRef] [PubMed] 
44. Looft, T.; Allen, H.K. Collateral effects of antibiotics on mammalian gut microbiomes. Gut Microbes 2012, 3, 463-467. [CrossRef] [PubMed]

45. Willing, B.P.; Russell, S.L.; Finlay, B.B. Shifting the balance: Antibiotic effects on host-microbiota mutualism. Nat. Rev. Genet. 2011, 9, 233-243. [CrossRef] [PubMed]

46. Modi, S.R.; Collins, J.J.; Relman, D.A. Antibiotics and the gut microbiota. J. Clin. Investig. 2014, 124, 4212-4218. [CrossRef] [PubMed]

47. Cash, H.L.; Whitham, C.V.; Behrendt, C.L.; Hooper, L.V. Symbiotic Bacteria Direct Expression of an Intestinal Bactericidal Lectin. Science 2006, 313, 1126-1130. [CrossRef]

48. Hooper, L.V.; Stappenbeck, T.S.; Hong, C.V.; Gordon, J.I. Angiogenins: A new class of microbicidal proteins involved in innate immunity. Nat. Immunol. 2003, 4, 269-273. [CrossRef]

49. Schauber, J.; Svanholm, C.; Termén, S.; Iffland, K.; Menzel, T.; Scheppach, W.; Melcher, R.; Agerberth, B.; Lührs, H.; Gudmundsson, G.H. Expression of the cathelicidin LL-37 is modulated by short chain fatty acids in colonocytes: Relevance of signalling pathways. Gut 2003, 52, 735-741. [CrossRef]

50. Evenepoel, P.; Meijers, B.K.; Bammens, B.R.; Verbeke, K. Uremic toxins originating from colonic microbial metabolism. Kidney Int. 2009, 76, S12-S19. [CrossRef]

51. Bennett, B.J.; Vallim, T.Q.D.A.; Wang, Z.; Shih, D.M.; Meng, Y.; Gregory, J.; Allayee, H.; Lee, R.; Graham, M.; Crooke, R.; et al. Trimethylamine-N-Oxide, a Metabolite Associated with Atherosclerosis, Exhibits Complex Genetic and Dietary Regulation. Cell Metab. 2013, 17, 49-60. [CrossRef] [PubMed]

52. Mutsaers, H.A.M.; Stribos, E.G.D.; Glorieux, G.; Vanholder, R.; Olinga, P. Chronic Kidney Disease and Fibrosis: The Role of Uremic Retention Solutes. Front. Med. 2015, 2, 60. [CrossRef] [PubMed]

53. Krogius-Kurikka, L.; Lyra, A.; Malinen, E.; Aarnikunnas, J.; Tuimala, J.; Paulin, L.; Mäkivuokko, H.; Kajander, K.; Palva, A. Microbial community analysis reveals high level phylogenetic alterations in the overall gastrointestinal microbiota of diarrhoea-predominant irritable bowel syndrome sufferers. BMC Gastroenterol. 2009, 9, 95. [CrossRef] [PubMed]

54. Salonen, A.; De Vos, W.M.; Palva, A. Gastrointestinal microbiota in irritable bowel syndrome: Present state and perspectives. Microbiology 2010, 156, 3205-3215. [CrossRef] [PubMed]

55. Ananthakrishnan, A.N. Epidemiology and risk factors for IBD. Nat. Rev. Gastroenterol. Hepatol. 2015, 12, 205-217. [CrossRef] [PubMed]

56. Wędrychowicz, A.; Zając, A.; Tomasik, P. Advances in nutritional therapy in inflammatory bowel diseases: Review. World J. Gastroenterol. 2016, 22, 1045-1066. [CrossRef] [PubMed]

57. Bellavia, M.; Tomasello, G.; Romeo, M.; Damiani, P.; Monte, A.I.L.; Lozio, L.; Campanella, C.; Gammazza, A.M.; Rappa, F.; Zummo, G.; et al. Gut microbiota imbalance and chaperoning system malfunction are central to ulcerative colitis pathogenesis and can be counteracted with specifically designed probiotics: A working hypothesis. Med. Microbiol. Immunol. 2013, 202, 393-406. [CrossRef] [PubMed]

58. SAME AS 8 Khan, I.; Ullah, N.; Zha, L.; Bai, Y.; Khan, A.; Zhao, T.; Che, T.; Zhang, C. Alteration of Gut Microbiota in Inflammatory Bowel Disease (IBD): Cause or Consequence? IBD Treatment Targeting the Gut Microbiome. Pathogens 2019, 8, 126. [CrossRef]

59. Franks, P.W.; McCarthy, M.I. Exposing the exposures responsible for type 2 diabetes and obesity. Science 2016, 354, 69-73. [CrossRef]

60. Lazar, V.; Ditu, L.M.; Pircalabioru, G.G.; Picu, A.; Petcu, L.; Cucu, N.; Chifiriuc, M.C. Gut Microbiota, Host Organism, and Diet Trialogue in Diabetes and Obesity. Front. Nutr. 2019, 6, 21. [CrossRef]

61. Burcelin, R. Gut microbiota and immune crosstalk in metabolic disease. Mol. Metab. 2016, 5, 771-781. [CrossRef] [PubMed]

62. Gomes, J.M.G.; Costa, J.A.; Alfenas, R.C.G. Metabolic endotoxemia and diabetes mellitus: A systematic review. Metabolism 2017, 68, 133-144. [CrossRef] [PubMed]

63. Blandino, G.; Inturri, R.; Lazzara, F.; Di Rosa, M.; Malaguarnera, L. Impact of gut microbiota on diabetes mellitus. Diabetes Metab. 2016, 42, 303-315. [CrossRef] [PubMed]

64. Vrieze, A.; Van Nood, E.; Holleman, F.; Salojärvi, J.; Kootte, R.S.; Bartelsman, J.F.; Dallinga-Thie, G.M.; Ackermans, M.T.; Serlie, M.J.; Oozeer, R.; et al. Transfer of Intestinal Microbiota from Lean Donors Increases Insulin Sensitivity in Individuals with Metabolic Syndrome. Gastroenterology 2012, 143, 913-916. [CrossRef] [PubMed] 
65. Walker, A.W.; Ince, J.; Duncan, S.H.; Webster, L.M.; Holtrop, G.; Ze, X.; Brown, D.; Stares, M.D.; Scott, P.; Bergerat, A.; et al. Dominant and diet-responsive groups of bacteria within the human colonic microbiota. ISME J. 2011, 5, 220. [CrossRef] [PubMed]

66. Han, X.; Shen, T.; Lou, H. Dietary Polyphenols and Their Biological Significance. Int. J. Mol. Sci. 2007, 8, 950-988. [CrossRef]

67. Kumar, R.; Singh, A.K.; Pandey, A.K. Phenolics. In Secondary Metabolite and Functional Food Components: Role in Health and Disease; Kumar, S., Ed.; Nova Biomedical: New York, NY, USA, 2018; pp. 13-32.

68. Appeldoorn, M.M.; Vincken, J.-P.; Gruppen, H.; Hollman, P.C.H. Procyanidin Dimers A1, A2, and B2 Are Absorbed without Conjugation or Methylation from the Small Intestine of Rats. J. Nutr. 2009, 139, 1469-1473. [CrossRef] [PubMed]

69. Cardona, F.; Andres-Lacueva, C.; Tulipani, S.; Tinahones, F.J.; Queipo-Ortuño, M.I. Benefits of polyphenols on gut microbiota and implications in human health. J. Nutr. Biochem. 2013, 24, 1415-1422. [CrossRef]

70. Lee, H.C.; Jenner, A.M.; Low, C.S.; Lee, Y.K. Effect of tea phenolics and their aromatic fecal bacterial metabolites on intestinal microbiota. Res. Microbiol. 2006, 157, 876-884. [CrossRef]

71. Tzounis, X.; Rodriguez-Mateos, A.; Vulevic, J.; Gibson, G.R.; Kwik-Uribe, C.; Spencer, J.P. Prebiotic evaluation of cocoa-derived flavanols in healthy humans by using a randomised, controlled, double-blind, crossover intervention study. Am. J. Clin. Nutr. 2011, 93, 62-72. [CrossRef]

72. Manach, C.; Williamson, G.; Morand, C.; Scalbert, A.; Remesy, C. Bioavailability and bioefficacy of polyphenols in humans. I. Review of 97 bioavailability studies. Am. J. Clin. Nutr. 2005, 81, 230S-242S. [CrossRef] [PubMed]

73. Bowey, E.; Adlercreutz, H.; Rowland, I. Metabolism of isoflavones and lignans by the gut microflora: A study in germ-free and human flora associated rats. Food Chem. Toxicol. 2003, 41, 631-636. [CrossRef]

74. Stapleton, P.D.; Shah, S.; Ehlert, K.; Hara, Y.; Taylor, P.W. The beta-lactam-resistance modifier (-)-epicatechin gallate alters the architecture of the cell wall of Staphylococcus aureus. Microbiology 2007, 153, 2093. [CrossRef] [PubMed]

75. Tombola, F.; Campello, S.; De Luca, L.; Ruggiero, P.; Del Giudice, G.; Papini, E.; Zoratti, M. Plant polyphenols inhibit VacA, a toxin secreted by the gastric pathogen Helicobacter pylori. FEBS Lett. 2003, 543, 184-189. [CrossRef]

76. Etxeberria, U.; Arias, N.; Boqué, N.; Macarulla, M.; Portillo, M.; Martinez, J.; Milagro, F. Reshaping faecal gut microbiota composition by the intake of trans-resveratrol and quercetin in high-fat sucrose diet-fed rats. J. Nutr. Biochem. 2015, 26, 651-660. [CrossRef] [PubMed]

77. Dolara, P.; Luceri, C.; De Filippo, C.; Femia, A.P.; Giovannelli, L.; Caderni, G.; Cecchini, C.; Silvi, S.; Orpianesi, C.; Cresci, A. Red wine polyphenols influence carcinogenesis, intestinal microflora, oxidative damage and gene expression profiles of colonic mucosa in F344 rats. Mutat. Res. Mol. Mech. Mutagen. 2005, 591, 237-246. [CrossRef]

78. Kang, N.J.; Lee, K.W.; Kim, B.H.; Bode, A.M.; Lee, H.-J.; Heo, Y.-S.; Boardman, L.; Limburg, P.; Lee, H.J.; Dong, Z. Coffee phenolic phytochemicals suppress colon cancer metastasis by targeting MEK and TOPK. Carcinogenesis 2011, 32, 921-928. [CrossRef]

79. Sengottuvelan, M.; Nalini, N. Dietary supplementation of resveratrol suppresses colonic tumour incidence in 1,2-dimethylhydrazine-treated rats by modulating biotransforming enzymes and aberrant crypt foci development. Br. J. Nutr. 2006, 96, 145-153. [CrossRef]

80. Larrosa, M.; Yañéz-Gascón, M.J.; Selma, M.V.; González-Sarrías, A.; Toti, S.; Cerónm, J.J.; Tomás-Barberán, F.; Dolara, P.; Espín, J.C. Effect of a Low Dose of Dietary Resveratrol on Colon Microbiota, Inflammation and Tissue Damage in a DSS-Induced Colitis Rat Model. J. Agric. Food Chem. 2009, 57, 2211-2220. [CrossRef]

81. Chan, C.-L.; Gan, R.-Y.; Shah, N.P.; Corke, H. Polyphenols from selected dietary spices and medicinal herbs differentially affect common food-borne pathogenic bacteria and lactic acid bacteria. Food Control 2018, 92, 437-443. [CrossRef]

82. Lin, G.; Yan, X.; Liu, D.; Yang, C.; Huang, Y.; Zhao, C. Role of green macroalgae enteromorpha prolifera polyphenols in the modulation of gene expression and intestinal microflora profiles in type 2 diabetic mice. Int. J. Mol. Sci. 2019, 20, 25. [CrossRef] [PubMed]

83. Wang, K.; Jin, X.; Li, Q.; Sawaya, A.C.H.F.; Le Leu, R.K.; Conlon, M.A.; Wu, L.; Hu, F. Propolis from Different Geographic Origins Decreases Intestinal Inflammation and Bacteroides spp. Populations in a Model of DSS-Induced Colitis. Mol. Nutr. Food Res. 2018, 62, e1800080. [CrossRef] [PubMed] 
84. Wang, K.; Wan, Z.; Ou, A.; Liang, X.; Guo, X.; Zhang, Z.; Wu, L.; Xue, X. Monofloral honey from a medical plant, Prunella Vulgaris, protected against dextran sulfate sodium-induced ulcerative colitis via modulating gut microbial populations in rats. Food Funct. 2019, 10, 3828-3838. [CrossRef] [PubMed]

85. Jayachandran, M.; Xiao, J.; Xu, B. A Critical Review on Health Promoting Benefits of Edible Mushrooms through Gut Microbiota. Int. J. Mol. Sci. 2017, 18, 1934. [CrossRef] [PubMed]

86. Tzounis, X.; Vulevic, J.; Kuhnle, G.G.; George, T.; Leonczak, J.; Gibson, G.R.; Kwik-Uribe, C.; Spencer, J.P. Flavanol monomer-induced changes to the human faecal microflora. Br. J. Nutr. 2008, 99, 782-792. [CrossRef]

87. Yamakoshi, J.; Tokutake, S.; Kikuchi, M.; Kubota, Y.; Konishi, H.; Mitsuoka, T. Effect of Proanthocyanidin-Rich Extract from Grape Seeds on Human Fecal Flora and Fecal Odor. Microb. Ecol. Heal. Dis. 2001, 13, $25-31$.

88. Snopek, L.; Mlcek, J.; Sochorova, L.; Baron, M.; Hlavacova, I.; Jurikova, T.; Kizek, R.; Sedlackova, E.; Sochor, J. Contribution of Red Wine Consumption to Human Health Protection. Molecules 2018, 23, 1684. [CrossRef] [PubMed]

89. Rastmanesh, R. High polyphenol, low probiotic diet for weight loss because of intestinal microbiota interaction. Chem. Interact. 2011, 189, 1-8. [CrossRef]

90. Monagas, M.; Khan, N.; Andres-Lacueva, C.; Urpi-Sarda, M.; Vázquez-Agell, M.; Lamuela-Raventos, R.M.; Estruch, R. Dihydroxylated phenolic acids derived from microbial metabolism reduce lipopolysaccharide-stimulated cytokine secretion by human peripheral blood mononuclear cells. Br. J. Nutr. 2009, 102, 201-206. [CrossRef]

91. Zanzer, Y.C.; Plaza, M.; Dougkas, A.; Turner, C.; Björck, I.; Östman, E. Polyphenol-rich spice-based beverages modulated postprandial early glycaemia, appetite and PYY after breakfast challenge in healthy subjects: A randomised, single blind, crossover study. J. Funct. Food 2017, 35, 574-583. [CrossRef]

92. González, J.E.; Keshavan, N.D. Messing with Bacterial Quorum Sensing. Microbiol. Mol. Boil. Rev. 2006, 70, 859-875. [CrossRef] [PubMed]

93. Lin, Y.T.; Kwon, Y.I.; Labbe, R.G.; Shetty, K. Inhibition of Helicobacter pylori and Associated Urease by Oregano and Cranberry Phytochemical Synergies. Appl. Environ. Microbiol. 2005, 71, 8558-8564. [CrossRef] [PubMed]

94. Cushnie, T.T.; Lamb, A.J. Antimicrobial activity of flavonoids. Int. J. Antimicrob. Agents 2005, 26, 343-356. [CrossRef] [PubMed]

95. Plaper, A.; Golob, M.; Hafner, I.; Oblak, M.; Solmajer, T.; Jerala, R. Characterization of quercetin binding site on DNA gyrase. Biochem. Biophys. Res. Commun. 2003, 306, 530-536. [CrossRef]

96. Fogliano, V.; Corollaro, M.L.; Vitaglione, P.; Napolitano, A.; Ferracane, R.; Travaglia, F.; Arlorio, M.; Costabile, A.; Klinder, A.; Gibson, G. In vitro bioaccessibility and gut biotransformation of polyphenols present in the water-insoluble cocoa fraction. Mol. Nutr. Food Res. 2011, 55, S44-S55. [CrossRef] [PubMed]

97. Self, W.T. Regulation of Purine Hydroxylase and Xanthine Dehydrogenase from Clostridium purinolyticum in Response to Purines, Selenium, and Molybdenum. J. Bacteriol. 2002, 184, 2039-2044. [CrossRef]

98. Verzelloni, E.; Pellacani, C.; Tagliazucchi, D.; Tagliaferri, S.; Calani, L.; Costa, L.G.; Brighenti, F.; Borges, G.; Crozier, A.; Conte, A.; et al. Antiglycative and neuroprotective activity of colon-derived polyphenol catabolites. Mol. Nutr. Food Res. 2011, 55, S35-S43. [CrossRef]

99. Macdonald, R.S.; Wagner, K. Influence of Dietary Phytochemicals and Microbiota on Colon Cancer Risk. J. Agric. Food Chem. 2012, 60, 6728-6735. [CrossRef]

100. Namasivayam, N. Chemoprevention in experimental animals. Ann. N. Y. Acad. Sci. 2011, 1215, 60-71. [CrossRef]

101. Miene, C.; Weise, A.; Glei, M. Impact of Polyphenol Metabolites Produced by Colonic Microbiota on Expression of COX-2 and GSTT2 in Human Colon Cells (LT97). Nutr. Cancer 2011, 63, 653-662. [CrossRef]

102. Madureira, A.R.; Nunes, S.; A Campos, D.; Fernandes, J.C.; Marques, C.; Zuzarte, M.; Gullon, B.; Rodríguez-Alcalá, L.M.; Calhau, C.; Sarmento, B.; et al. Safety profile of solid lipid nanoparticles loaded with rosmarinic acid for oral use: In vitro and animal approaches. Int. J. Nanomed. 2016, 11, 3621-3640.

103. Nunes, S.; Madureira, A.R.; Campos, D.; Sarmento, B.; Gomes, A.M.; Pintado, M.; Reis, F. Solid lipid nanoparticles as oral delivery systems of phenolic compounds: Overcoming pharmacokinetic limitations for nutraceutical applications. Crit. Rev. Food Sci. Nutr. 2017, 57, 1863-1873. [CrossRef] [PubMed]

104. Nunes, S.; Madureira, A.R.; Campos, D.; Sarmento, B.; Gomes, A.M.; Pintado, M.; Reis, F. Therapeutic and nutraceutical potential of rosmarinic acid-Cytoprotective properties and pharmacokinetic profile. Crit. Rev. Food Sci. Nutr. 2017, 57, 1799-1806. [CrossRef] [PubMed] 
105. Kotla, N.G.; Rana, S.; Sivaraman, G.; Sunnapu, O.; Vemula, P.K.; Pandit, A.; Rochev, Y. Bioresponsive drug delivery systems in intestinal inflammation: State-of-the-art and future perspectives. Adv. Drug Deliv. Rev. 2018. [CrossRef] [PubMed]

106. Lautenschläger, C.; Schmidt, C.; Fischer, D.; Stallmach, A. Drug delivery strategies in the therapy of inflammatory bowel disease. Adv. Drug Deliv. Rev. 2014, 71, 58-76. [CrossRef]

107. Carbone, C.; Manno, D.; Serra, A.; Musumeci, T.; Pepe, V.; Tisserand, C.; Puglisi, G. Innovative hybrid vs polymeric nanocapsules: The influence of the cationic lipid coating on the " $4 S^{\prime}$. Colloids Surfaces $B$ Biointerfaces 2016, 141, 450-457. [CrossRef] [PubMed]

108. Puglia, C.; Lauro, M.R.; Tirendi, G.G.; Fassari, G.E.; Carbone, C.; Bonina, F.; Puglisi, G. Modern drug delivery strategies applied to natural active compounds. Expert Opin. Drug Deliv. 2017, 14, 755-768. [CrossRef]

109. Chung, J.-H.; Lee, S.-J.; Chung, J.-O.; Oh, Y.-J.; Hwang, J.-A.; Kim, Y.-K.; Ko, S.; Shim, S.-M. Effect of hydroxypropyl methyl cellulose phthalate coating on digestive stability and intestinal transport of green tea catechins. Integr. Med. Res. 2014, 3, 34-37. [CrossRef]

110. Xiao, B.; Si, X.; Zhang, M.; Merlin, D. Oral administration of pH-sensitive curcumin-loaded microparticles for ulcerative colitis therapy. Colloids Surfaces B Biointerfaces 2015, 135, 379-385. [CrossRef]

111. Lozano-Perez, A.A.; Rodriguez-Nogales, A.; Ortiz-Cullera, V.; Algieri, F.; Garrido-Mesa, J.; Zorrilla, P.; Rodriguez-Cabezas, M.E.; Garrido-Mesa, N.; Utrilla, M.P.; De Matteis, L.; et al. Silk fibroin nanoparticles constitute a vector for controlled release of resveratrol in an experimental model of inflammatory bowel disease in rats. Int. J. Nanomed. 2014, 9, 4507-4520.

112. Shinde, T.; Sun-Waterhouse, D.; Brooks, J. Co-extrusion Encapsulation of Probiotic Lactobacillus acidophilus Alone or Together with Apple Skin Polyphenols: An Aqueous and Value-Added Delivery System Using Alginate. Food Bioprocess Technol. 2014, 7, 1581-1596. [CrossRef]

113. Fratianni, F.; Cardinale, F.; Russo, I.; Iuliano, C.; Tremonte, P.; Coppola, R.; Nazzaro, F. Ability of synbiotic encapsulatedSaccharomyces cerevisiae boulardiito grow in berry juice and to survive under simulated gastrointestinal conditions. J. Microencapsul. 2014, 31, 299-305. [CrossRef] [PubMed]

114. Fleschhut, J.; Kratzer, F.; Rechkemmer, G.; Kulling, S.E. Stability and biotransformation of various dietary anthocyanins in vitro. Eur. J. Nutr. 2006, 45, 7-18. [CrossRef] [PubMed]

115. Faria, A.; Fernandes, I.; Norberto, S.; Mateus, N.; Calhau, C. Interplay between Anthocyanins and Gut Microbiota. J. Agric. Food Chem. 2014, 62, 6898-6902. [CrossRef] [PubMed]

116. Morais, C.A.; De Rosso, V.V.; Estadella, D.; Pisani, L.P.; Information, P.E.K.F.C. Anthocyanins as inflammatory modulators and the role of the gut microbiota. J. Nutr. Biochem. 2016, 33, 1-7. [CrossRef] [PubMed] 